\title{
The Mechanisms of Disease Caused by Acinetobacter baumannii
}

\author{
Faye C. Morris ${ }^{1}$, Carina Dexter ${ }^{1}$, Xenia Kostoulias ${ }^{1}$, Muhammad Ikhtear Uddin ${ }^{1}$ and \\ Anton Y. Peleg ${ }^{1,2 *}$
}

IInfection and Immunity Program, Department of Microbiology, Monash Biomedicine Discovery Institute, Monash University, Clayton, VIC, Australia, 'Department of Infectious Diseases, The Alfred Hospital and Central Clinical School, Monash University, Melbourne, VIC, Australia

OPEN ACCESS

Edited by:

Maria Alejandra Mussi, National Council for Scientific and Technical Research (CONICET), Argentina

Reviewed by: Jason Sahl,

Northern Arizona University, United States

Jose Ramos-Vivas, Instituto de Investigación Marques de Valdecilla (IDIVAL), Spain

${ }^{*}$ Correspondence: Anton Y. Peleg anton.peleg@monash.edu

Specialty section: This article was submitted to Infectious Diseases, a section of the journal Frontiers in Microbiology

Received: 15 January 2019 Accepted: 26 June 2019 Published: 17 July 2019

Citation:

Morris FC, Dexter C, Kostoulias X, Uddin MI and Peleg AY (2019) The Mechanisms of Disease Caused by Acinetobacter baumannii. Front. Microbiol. 10:1601. doi: 10.3389/fmicb.2019.01601
Acinetobacter baumannii is a Gram negative opportunistic pathogen that has demonstrated a significant insurgence in the prevalence of infections over recent decades. With only a limited number of "traditional" virulence factors, the mechanisms underlying the success of this pathogen remain of great interest. Major advances have been made in the tools, reagents, and models to study $A$. baumannii pathogenesis, and this has resulted in a substantial increase in knowledge. This article provides a comprehensive review of the bacterial virulence factors, the host immune responses, and animal models applicable for the study of this important human pathogen. Collating the most recent evidence characterizing bacterial virulence factors, their cellular targets and genetic regulation, we have encompassed numerous aspects important to the success of this pathogen, including membrane proteins and cell surface adaptations promoting immune evasion, mechanisms for nutrient acquisition and community interactions. The role of innate and adaptive immune responses is reviewed and areas of paucity in our understanding are highlighted. Finally, with the vast expansion of available animal models over recent years, we have evaluated those suitable for use in the study of Acinetobacter disease, discussing their advantages and limitations.

Keywords: A. baumannii, host-pathogen interactions, animal models, immune response, bacterial virulence factors

\section{INTRODUCTION}

Acinetobacter baumannii is a Gram negative, obligate aerobe, coccobacillus, and one of the most prevalent causes of nosocomial infections (Martín-Aspas et al., 2018). The burgeoning resistance of $A$. baumannii to primary antimicrobial therapies has created a deadly combination of pathogenicity and antimicrobial resistance that plagues hospitals (Roca et al., 2012). Classified as an ESKAPE pathogen (Enterococcus faecium, Staphylococcus aureus, Klebsiella pneumoniae, Acinetobacter baumannii, Pseudomonas aeruginosa, and Enterobacter species), carbapenem-resistant A. baumannii is considered the World Health Organization's number one critical priority pathogen for which new therapeutics are urgently required (Shlaes and Bradford, 2018). Concerns continue to grow that without a significant intervention, hospital-acquired A. baumannii infections will soon be untreatable.

Acinetobacter phylogenetics has undergone significant changes, originally described as Micrococcus, with the designation of Acinetobacter only being proposed in the 1950's (Peleg et al., 2008a). Since then, Acinetobacter taxonomy has been reclassified and over 50 different species have been identified to date (Harding et al., 2017a). While A. baumannii, A. nosocomialis 
and $A$. pittii are the most commonly isolated hospital species, A. baumannii international clonal types 1 and 2 are the most prominent, with lineage 3 largely restricted to Europe (Wallace et al., 2016; Weber et al., 2016). For more information on genomic diversity, the reader is directed to the following articles (Diancourt et al., 2010; Antunes et al., 2014; Touchon et al., 2014; Meumann et al., 2019).

With only a limited number of "traditional" virulence factors, which are not always present or conserved across all strains, the mechanisms contributing to the success of $A$. baumannii are of increasing interest to researchers and clinicians alike. This article summarizes the knowledge of characterized virulence factors (depicted in Figure 1) and the host immune responses (depicted in Figure 2) that contribute to both its success and clearance in vivo, with a final overview of the available animal models, evaluating their advantages and limitations.

\section{CLINICAL SIGNIFICANCE}

A. baumannii causes a range of infections in both the hospital and community, including skin and soft tissue, urinary tract infections, meningitis, bacteremia, and pneumonia, with the latter being the most frequently reported infection in both settings (Dexter et al., 2015). Hospital-acquired infections are most commonly seen in critically ill patients; specific risk factors for developing an A. baumannii infection include prolonged hospital stays, immune suppression, advanced age, presence of comorbid diseases, major trauma or burns, previous antibiotic use, invasive procedures, and presence of indwelling catheters or mechanical ventilation (García-Garmendia et al., 2001; Robenshtok et al., 2006; Karageorgopoulos and Falagas, 2008; Wong et al., 2017). Due to the already poor prognosis of critically ill patients who acquire A. baumannii infections, it is difficult to attribute a definitive mortality rate (Freire et al., 2016); however crude morality rates have ranged from 23 to $68 \%$ (Eliopoulos et al., 2008).

Community-acquired infections present as a distinct and severe clinical syndrome in countries with hot and humid climates. These infections typically occur in individuals with underlying health conditions, including diabetes mellitus and chronic obstructive pulmonary disease, or in those that are heavy smokers or drink alcohol in excess (Falagas et al., 2007; Dexter et al., 2015). Mortality rates for community-acquired A. baumannii infections have been reported as high as $64 \%$ (Anstey et al., 1992; Patamatamkul et al., 2017); however, it is currently unknown as to whether host or bacterial factors are responsible for the difference in disease presentation between community and hospital infections.

\section{BACTERIAL PATHOGENESIS}

\section{Virulence Factors \\ Outer Membrane Components}

Outer Membrane Proteins

Outer membrane protein A (OmpA, previously Omp38) is the most abundant $A$. baumannii outer membrane protein (OMP)

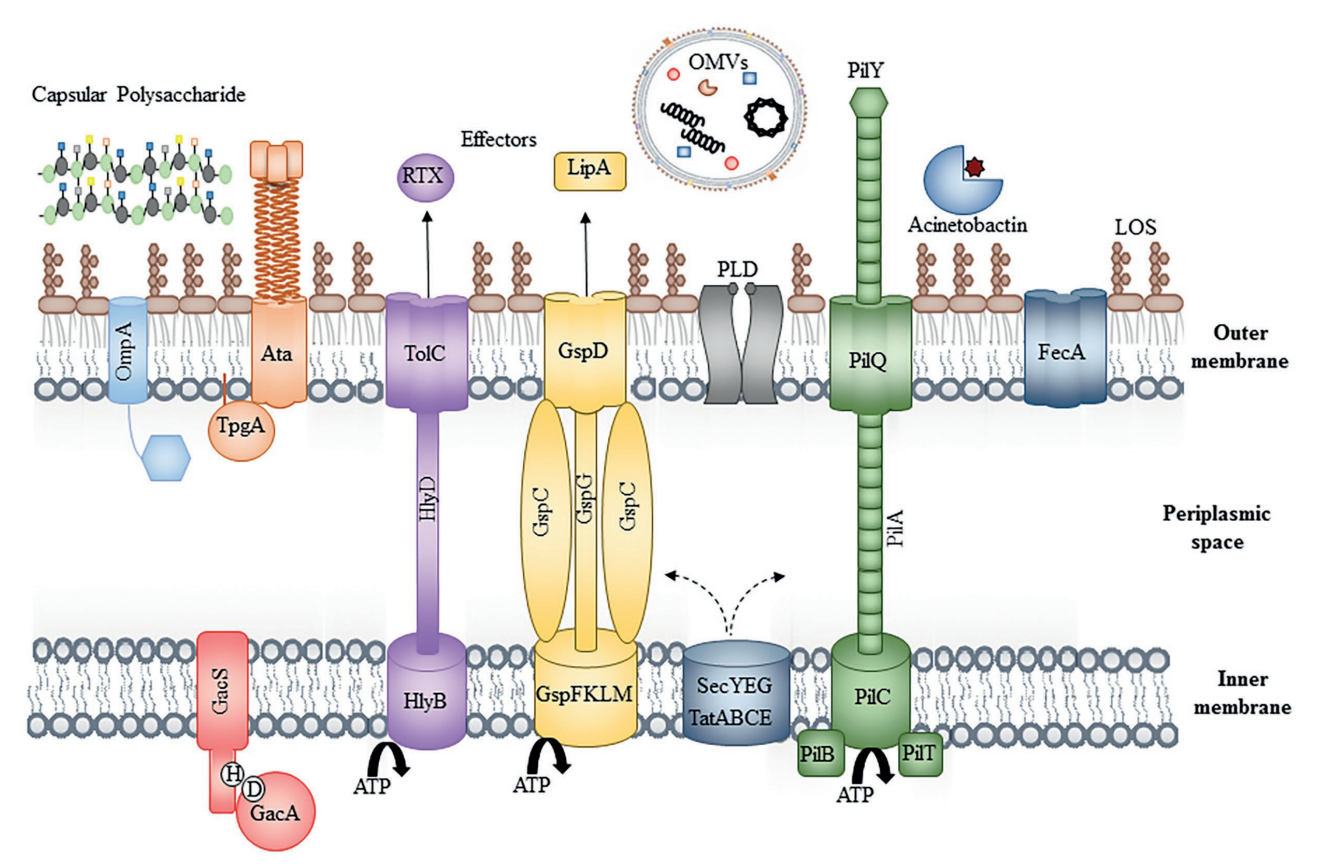

FIGURE 1 | Bacterial virulence factors. Schematic of the bacterial cell envelope depicting some of the known virulence factors, including OmpA, the Type II, IV, and $V$ secretion systems, phospholipase D (PLD), iron acquisition systems (Acinetobactin and FecA), the inner membrane two-component system, GacAS and extracellular factors, including lipid oligosaccharide, capsular polysaccharide, and outer membrane vesicles. For simplicity, peptidoglycan has been excluded and individual components are not to scale. 


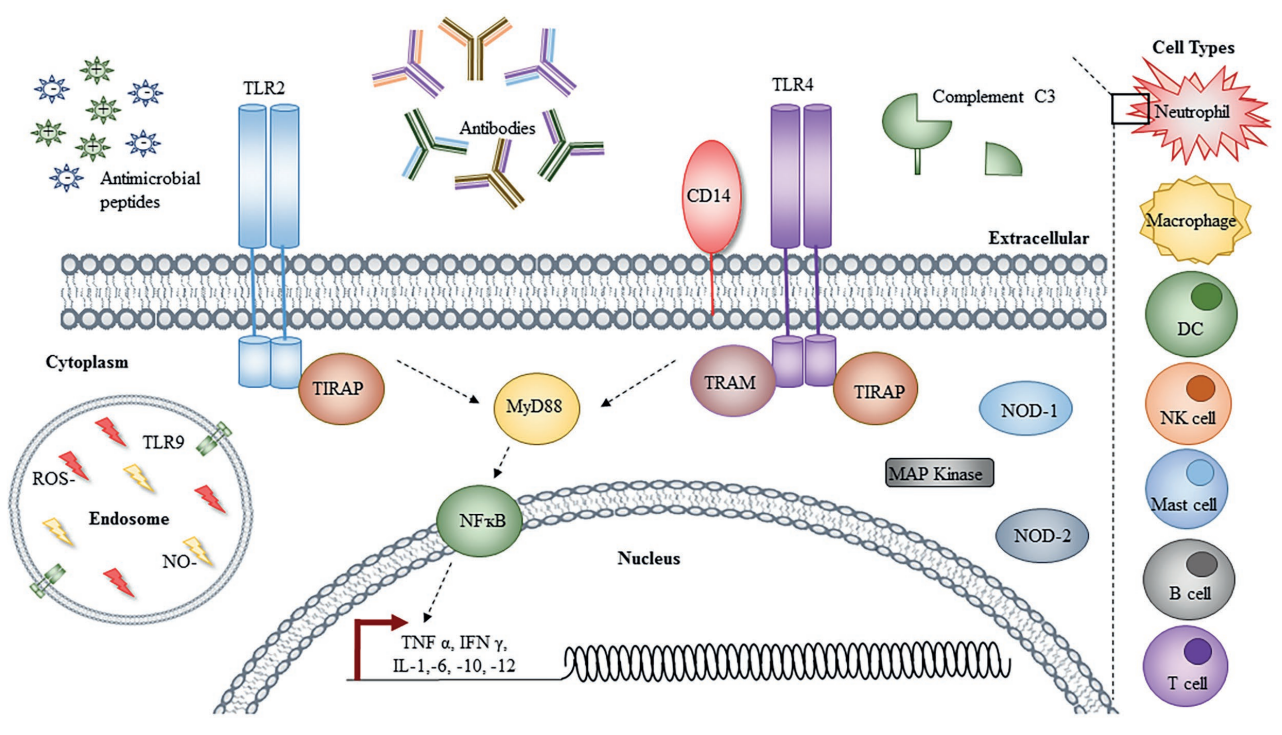

FIGURE 2 | Immune responses to Acinetobacter. Immune cells involved in the clearance of Acinetobacter infections are denoted on the right-hand side, with an insert depicting the cellular components responsible. The toll-like receptor (TLR) 2 and 4 signaling leads to activation of NFKB via MyD88, resulting in transcriptional activation and the synthesis of a range of cytokines and chemokines. Other cytoplasmic proteins shown to be involved in response to Acinetobacter infection are highlighted, with TLR9 localized to the endosome, in conjugation with reactive oxygen species (ROS) and nitric oxide (NO). Extracellular components, including cationic and anionic antimicrobial peptides, antibodies, and C3 complement are depicted left to right. For simplicity, not all proteins involved in the TLR signaling pathways are depicted and individual components are not to scale.

(Hee et al., 2008) and one of the most well-characterized virulence factors. OmpA is highly conserved, with 83 of 103 clinical isolates showing greater than $99 \%$ sequence identity, with the most diverse having 85\% sequence identity (Ahmad et al., 2016; Ansari et al., 2018; Iyer et al., 2018). As such, OmpA has often been promoted as an attractive target for vaccine development. OmpA forms an eight-stranded $\beta$ barrel in the OM, with a 2-nm pore diameter and C-terminal periplasmic globular extension, accommodating molecules up to $500 \mathrm{Da}$ (Sugawara and Nikaido, 2012; Iyer et al., 2018). In contrast to other major porins, such as $\mathrm{OmpF} / \mathrm{C}$ from E. coli, A. baumannii OmpA has significantly reduced permeability, thought to contribute to the overall reduction in A. baumannii OM permeability (Sugawara and Nikaido, 2012). To date, only the C-terminal periplasmic domain has been crystalized (1.6 $⿱$ ) and shown to directly interact with peptidoglycan through Asp271 and Arg286 binding to diaminopimelate (Park et al., 2012). This interaction is thought to influence the packing of OMPs into outer membrane vesicles (OMVs), though this has yet to be confirmed, and may be merely a consequence of altered membrane homeostasis in an ompA mutant (Moon et al., 2012).

During normal growth and in vivo infection, OmpA is preferentially concentrated into OMVs (Moon et al., 2012). The interaction of OmpA (on the bacterial cell surface or OMVs) with eukaryotic cells induces cytotoxicity, through binding and adhesion to eukaryotic cell surface death receptors (Ahmad et al., 2016). Upon internalization, OmpA translocates to either the mitochondria or the nucleus (Hee et al., 2005, 2008; Rumbo et al., 2014). In the mitochondria, OmpA induces proapoptotic signals, through the activation of Bcl-2 family proteins, the release of cytochrome $\mathrm{C}$ and apoptosis-inducing factor (Hee et al., 2005). OmpA can also be translocated to the nucleus courtesy of its self-encoded nuclear localization signal (KTKEGRAMNRR), which is absent from other A. baumannii OMPs, and causes host DNA degradation in a DNase I-like manner (Hee et al., 2008; Choi et al., 2008a; Rumbo et al., 2014). In addition to its cytotoxic properties, OmpA modulates a range of other virulence attributes, including resistance to alternate complement-mediated killing through factor $\mathrm{H}$ binding and promoting adhesion to extracellular matrix proteins, including fibronectin, which is important for lung epithelial colonization (Kim et al., 2009; Smani et al., 2012).

Recent years have seen an expansion in our knowledge of other OMPs contributing to A. baumannii pathogenesis. Omp34 (otherwise termed Omp33-36) is highly conserved in A. baumannii, present in $>1,600$ strains with $\geq 98 \%$ identity (Rumbo et al., 2014). Similar to OmpA, Omp34 induces apoptosis in eukaryotic cells through caspase-dependent mechanisms and inhibition of autophagy, promoting bacterial persistence in the autophagosome (Rumbo et al., 2014; Jahangiri et al., 2018). Omp34 has also been shown to bind fibronectin and is selectively concentrated into OMVs (Smani et al., 2012). Shown to be important for systemic virulence in murine models, Omp34 is highly immunogenic, driving potent $\mathrm{IgA} / \mathrm{G} / \mathrm{M}$ antibody responses in sera from infected patients (Islam et al., 2011; Jahangiri et al., 2018). Additionally, OmpW also forms an eight-stranded OM $\beta$ barrel protein, which is both highly immunogenic and concentrated in OMVs, though the functional role of this protein is thought to be related to iron acquisition and antibiotic resistance (Huang et al., 2015; Manuella et al., 2016). 
Surface Antigen 1 (SurA) is another OMP that was identified from the chicken isolate CCGGD201101 (Liu et al., 2016). The relevance of this OMP to human clinical isolates is yet to be determined. While numerous other OMPs have been identified and characterized, these are discussed later in the context of bacterial nutrient acquisition, as they do not encode conventional virulence factors.

\section{Lipopolysaccharide, Lipoolgiosaccharide, and Capsule}

Similar to all other OM components, the Lipopolysaccharide (LPS), Lipoolgiosaccharide (LOS), and capsule are all synthesized in the cytoplasm and translocated to the outer leaflet of the cell envelop by dedicated proteinaceous machinery.

LPS is comprised of three distinct components: the lipid A anchor, glycosylated with core oligosaccharides, to which the $\mathrm{O}$-antigen repeat is attached. In contrast, LOS does not contain $\mathrm{O}$-antigen and instead has extended core oligosaccharides (Whitfield and Trent, 2014; Weber et al., 2016; Joseph and Stephen, 2018). Synthesized in the cytoplasm by the multistep Raetz pathway, both types are transported from the inner membrane to the cell surface by the Lpt pathway. Despite encoding two potential waaL O-antigen ligase homologs, A. baumannii does not produce O-antigen or LPS, and instead decorates the OM with LOS. Furthermore, subsequent analysis of these waaL genes has shown they are responsible for protein glycosylation (Iwashkiw et al., 2012).

Lipid A is the immunostimulatory component of LPS and LOS and previously thought to be essential in all Gram negative bacteria. Within the last decade, Acinetobacter has become only the third Gram negative pathogen capable of survival in the absence of lipid A, where previously only Neisseria meningitidis and Moraxella catarrhalis were thought to have this capacity (Moffatt et al., 2010). Lipid A minus A. baumannii was first identified in response to in vitro colistin exposure, resulting in inactivation of $l p x A, l p x C$, or $l p x D$ in ATCC 19606 (Moffatt et al., 2010). Interestingly, with the exception of $l p x A$, $l p x C, \quad l p x D$, and $l p t D$, all other LOS biosynthetic genes are essential due to the resultant accumulation of toxic intermediates (Joseph and Stephen, 2018). For several years, the loss of lipid A was thought to be restricted to specific A. baumannii strains; however, recent efforts have shown that the levels of penicillinbinding protein PBP1a and, specifically, its glycosyltransferase activity are critical to the ability to lose lipid A (Boll et al., 2016). As lipid A is the major stimulus for toll like receptor (TLR) 4, it is unsurprising that lipid A minus strains reduce TLR4 signaling, but elevate TLR2 stimulation (Moffatt et al., 2013), thought to be as a result of the increased OM lipoprotein exposure. In contrast to LOS deficiency, A. baumannii more frequently modifies the lipid A moiety to promote antimicrobial resistance. Unlike other Gram negative pathogens, A. baumannii does not encode a PagP homolog; therefore, modification of the hexa-acylated lipid A occurs through the addition of one and two lauryl acyl chains during synthesis by the activity of LpxL and LpxM, respectively (Boll et al., 2015; Lopalco et al., 2017). This modification results in hepta-acylated lipid A that is more resistant to cationic antimicrobial peptides, less stimulatory of TLR4 and implicated in desiccation survival
(Boll et al., 2015). By contrast to that of LOS minus strains, lipid A modification does not induce the same biological burden, and thus is readily detected in clinical isolates.

Capsule forms a protective layer on the extracellular surface, mediating resistance to cationic antimicrobial peptides and serum, subsequently enhancing in vivo survival (Geisinger and Isberg, 2015). Capsule loci in A. baumannii are highly variable, with conserved $5^{\prime}$ and $3^{\prime}$ genes capping the variable central cluster (Hu et al., 2013; Geisinger and Isberg, 2015). The 5' $w z a, w z b$, and $w z c$ encode the assembly and export machinery complex spanning the inner and outer membranes, promoting transport of capsular polysaccaride from the periplasm to the cell surface (Kenyon and Hall, 2013; Senchenkova et al., 2015). The $3^{\prime}$ genes encode UDP-linked sugar synthases and epimerases, responsible for the conversion of UDP-D-glucose, UDP-Dgalactose, and UDP-D-glucuronic acid to UDP-N acetyl-Dglucosaminuronic acid or UDP-N acetyl-D-galactosaminuronic acid, respectively (Hu et al., 2013; Kenyon and Hall, 2013). Other epimerases are encoded by central genes and/or at distinct sites around the chromosome, while glycosyltransferases and UndP lipid carriers responsible for the construction of the repeating unit, work in concert with wzx and wzy to translocate these components to the periplasm for polymerization and presentation to the Wzabc complex (Kenyon and Hall, 2013).

Capsule production is negatively regulated by the BfmRS two-component regulatory system (TCS) in response to environmental stimuli, including particular antibiotics (chloramphenicol and erythromycin), resulting in increased expression and antimicrobial resistance (Geisinger and Isberg, 2015). Furthermore, the presence or absence of capsule has also been linked to Acinetobacter phenotypic switching, whereby the opaque virulent form is characterized by enhanced capsule production, in contrast with the translucent avirulent form, which displays two-fold less capsule production (Chin et al., 2018).

\section{Phospholipase}

Phospholipases are well-established virulence factors and Acinetobacter encodes both phospholipase C and D enzymes, differentiated by their cleavage position preference resulting in a phospho head group (phospholipase C) or phosphatidic acid and a separate head group (phospholipase D) (Schmiel and Miller, 1999). A. baumannii encodes two phospholipase $C$ and three phospholipase D enzymes, all with substrate specificity toward the eukaryotic membrane component, phosphatidylcholine (Stahl et al., 2015; Fiester et al., 2016). Interestingly, both enzymes are transcriptionally regulated by the ferric uptake regulator (Fur) and display hemolytic activity against human erythrocytes, aiding in iron acquisition (Fiester et al., 2016). Consistent with this important role, phospholipase $\mathrm{C}$ is conserved across numerous strains, including ATCC 19606, ATCC 17978, ACICU, AYE, and AB0057 (Fiester et al., 2016).

Similarly, the three phospholipase D genes are associated with serum resistance, epithelial cell invasion, and in vivo pathogenesis (Jacobs et al., 2010; Stahl et al., 2015). Two phospholipase $\mathrm{D}$ enzymes appear to be as a result of a gene duplication, identifiable by two catalytic domains containing the $\mathrm{HxKx} 4 \mathrm{Dx} 6 \mathrm{GS} / \mathrm{GGxN}$ (HKD) motif, while phospholipase 
D3 contains only one (Stahl et al., 2015). Despite the similarity, phospholipase D2 has been shown to be more important for invasion than the other two, though the deletion of all three induces only marginal defects in virulence in a Galleria mellonella model (Stahl et al., 2015).

\section{Secretion Systems}

Acinetobacter encodes a diverse range of secretion systems. The Type I secretion system (T1SS) is a tripartite system, delivering proteins from the cytosol to the extracellular environment. In Acinetobacter, the T1SS is homologous to that of the prototypical HlyBD-TolC system from E. coli, consisting of an IM ATP-binding protein, periplasmic adaptor, and OM pore (Harding et al., 2017b). A. nosocomialis strain M2 was the first Acinetobacter strain shown to encode an active TiSS, with two putative effector proteins, RTX (containing an RTX toxin domain) and Bap (homologous to the biofilm associated protein) (Harding et al., 2017b). Interestingly, the activity of the T1SS in this strain was shown to have a direct impact on the Type VI secretion system (T6SS), suggestive of cross talk between these systems (Harding et al., 2017b).

The Type IV secretion system (T4SS) is responsible for conjugative transfer of DNA, plasmids, and other mobile genetic elements. To date, only three reports address the T4SS in Acinetobacter (Smith et al., 2007; Iacono et al., 2008; Liu et al., 2014). A. baumannii strain ATCC 17978 encodes eight genes homologous to those of the Legionella/Coxiella T4SS, while strains ACICU and TYTH-1 harbor plasmids encoding complete tra loci on pACICU2 and pAB-CC, respectively (Smith et al., 2007; Iacono et al., 2008; Liu et al., 2014). While these features are of critical importance in the transfer of genetic material, particularly that of antibiotic resistance determinants, their role in host-pathogen interactions has yet to be elucidated.

T6SSs are capable of targeting both eukaryotic and prokaryotic cells, though in Acinetobacter the T6SS exclusively targets other bacteria, secreting a range of toxins, including peptidoglycan hydrolases, nucleases, or those targeting cell membranes (Elhosseiny and Attia, 2018; Fitzsimons et al., 2018). Interestingly, despite its role in bacterial competition, clinical isolates with active T6SS are isolated from immunocompromised patients at higher frequencies (Repizo, 2017), suggestive of a competitive advantage, although this may be due to their bactericidal activity against competing pathogens.

\section{Type II Secretion System}

The Type II secretion system (T2SS) is a two step secretion mechanism, dependent on Sec or Tat for substrate translocation to the periplasm prior to secretion. The T2SS was first described in ATCC 17978, with the apparatus encoded by genes designated, general secretory pathway (GspA-O), distributed across discrete clusters and not a single operon (Eijkelkamp et al., 2014). Effector proteins include enzymes such as lipase, elastase, alkaline phosphatase, and phospholipases, critical for A. baumannii virulence (Elhosseiny and Attia, 2018).

In A. baumannii, specific T2SS effectors include the lipases, LipA and LipH, hydrolyzing long-chain fatty acids as carbon sources for growth, the metallo-endopeptidase, $\mathrm{CpaA}$, responsible for fibrinogen and factor $\mathrm{V}$ degradation, while the PilD peptidase is shared between the T2SS and T4SS (Harding et al., 2016; Johnson et al., 2016; Weber et al., 2017). The importance of this system is delineated by the observed attenuation of various mutants ( $g s p D$ and lipA) in both G. mellonella and murine models (Harding et al., 2016; Johnson et al., 2016).

\section{Type V Secretion System}

The Type V secretion system (T5SS) (autotransporters) is the simplest and most widespread secretion system in Gram negative bacteria (Henderson et al., 2000). They are identifiable by their distinct domain architecture, including a $\mathrm{N}$-terminal Sec-dependent signal peptide, a central passenger domain and C-terminal $\beta$ barrel (Henderson et al., 2004). To date, five subdivisions of this family have been identified termed Type Va-Ve (Leo et al., 2012); however, Acinetobacter encodes only two, Type $\mathrm{Vb}(\mathrm{AbFhaB} / \mathrm{C}$ and $\mathrm{CdiA} / \mathrm{B})$ and one Type Vc (Ata) (Bentancor et al., 2012a,b; Pérez et al., 2017; Elhosseiny and Attia, 2018).

In the Type $\mathrm{Vb}$ subclass, the passenger and $\beta$ domains are encoded as two distinct proteins from an operon termed TspA (AbFhaB) and TspB (AbFhaC), respectively (Jacob-Dubuisson et al., 2001; Pérez et al., 2017). AbFhaC encodes the 16-stranded $\beta$ barrel, with two periplasmic polypeptide transport-associated domains for the recognition and translocation of $\mathrm{AbFhaB}$ to the cell surface, where the arginine-glycine-aspartate (RGD) motif binds eukaryotic integrin and fibronectin molecules (Jacob-Dubuisson et al., 2009; Pérez et al., 2017). Interestingly, while disruption of $\mathrm{AbFhaC}$ and subsequent loss of $\mathrm{AbFhaB}$ result in increased fertility of Caenorhabditis elegans and increased murine survival, it does not completely attenuate virulence (Pérez et al., 2017).

Contact-dependent inhibition (CDI) was first identified in 2005 as a T6SS-independent mechanism of bacterial cell killing. $\mathrm{CdiA} / \mathrm{B}$ are considered to be Type $\mathrm{Vb}$ autotransporters, whereby $\mathrm{CdiB}$ forms the OM pore for the secretion of the CdiA toxin (containing numerous filamentous hemagglutinin domains) (Harding et al., 2017b). In contrast to traditional Type Vb autotransporters, a third component termed CdiI encodes an immunity protein (Harding et al., 2017b). Initially identified in A. nosocomialis, this operon has since been identified in the A. baumannii strains ATCC 19606 and 1225 (Harding et al., 2017b), although the mechanism of killing has yet to be determined.

Type Vc, Ata forms a trimeric autotransporter, with an extended signal peptide, and a smaller C-terminal $\beta$ domain. Each monomer encodes 101 amino acids, contributing four $\beta$ strands to the final homotrimer (Bentancor et al., 2012a). The passenger domain of each monomer consists of three subdomains, head, neck, and stalk, which trimerise to form the functional moiety (Koiwai et al., 2016). Ata contains four pentameric collagen-binding consensus sequences (SVAIG) and an RGD motif important for binding to extracellular matrix and basal proteins, including collagen I, III, IV, and V and laminin (Bentancor et al., 2012a). Deletion of this protein significantly reduces the ability of ATCC 17978 to form biofilms and completely attenuates in vivo virulence (Bentancor et al., 2012a). 
Interestingly, Ata is produced in concert with $\mathrm{Tpg} A$, an $\mathrm{OM}$ lipoprotein anchor for Ata and although similar chaperones have been observed for other trimeric autotransporters, TpgA is unique in its OM localization (Ishikawa et al., 2016).

\section{Efflux Systems}

Bacterial efflux systems are membrane spanning, tripartite systems exhibiting broad substrate specificity, extruding potentially toxic compounds from the periplasm to the extracellular environment. To date, six bacterial efflux pump families have been identified, including the major facilitator superfamily (MFS), the multidrug and toxin extrusion family (MATE), the small multidrug resistance family (SMR), the resistance-nodulation-cell division superfamily (RND), and the proteobacterial antimicrobial compound efflux family (Du et al., 2018). In other Gram negative pathogens, efflux pumps play critical roles in the extrusion of bile salts and antimicrobial fatty acids and peptides or actively secrete virulence factors such as siderophores (Du et al., 2018). In Acinetobacter, AceI and the AdeABC efflux pumps promote resistance to biocides and aminoglycosides, respectively (Marchand et al., 2004; Hassan et al., 2013; Liu et al., 2018). While the majority of characterized efflux pumps have only been linked to the exclusion of toxic molecules, the AdeABC pump has been shown to impact bacterial fitness in vivo (Yoon et al., 2016). Overexpression of this particular pump in the drug susceptible strain BM4587 was shown to reduce bacterial burdens in the lungs and spleen at $8 \mathrm{~h}$ post infection when administered via the intraperitoneal route (Yoon et al., 2016). Conversely, transposon insertion mutants in AdeIJK and the toluene tolerance efflux transporter in AB5075 and ATCC17978, respectively, result in reduced bacterial persistence in Galleria larvae and a murine pneumonia model (Wang et al., 2014; Gebhardt et al., 2015). Although the mechanisms by which these efflux pumps contribute to virulence have yet to be elucidated, their complex genetic regulation implies a more significant role in bacterial homeostasis that has yet to be determined.

\section{Outer Membrane Vesicles}

OMVs are small, spherical vesicles, ranging in size between 10 and $300 \mathrm{~nm}$, produced by all Gram negative species examined to date under varying growth conditions, indicative of an evolutionary conserved mechanism (Roier et al., 2016). In contrast to the name, these vesicles are an encapsulation of cytoplasmic components, IM, periplasmic proteins, and OM (Kulkarni and Jagannadham, 2014; Roier et al., 2016). Despite previously being considered a consequence of cell envelope stress, vesicle formation has recently been shown to be a natural process, though the exact mechanism of their biogenesis and differential packaging regarding the enrichment or depletion of particular OMPs or lipid species has yet to be determined (McBroom and Kuehn, 2005, 2007; Roier et al., 2016). It is unclear whether a dedicated mechanism exists or whether this is just a general secretory pathway responsive to different environmental conditions (Kato et al., 2002; Kuehn and Kesty, 2005; McMahon et al., 2012; Cahill et al., 2015). Currently, three hypotheses exist for their biogenesis: firstly, the loss of
OM lipoprotein-peptidoglycan interactions leads to membrane protrusion and vesicle formation; second, the accumulation of misfolded proteins and peptidoglycan fragments in the periplasm lead to membrane bulging; third, the enrichment of molecules driving membrane curvature induces vesicle formation (Roier et al., 2016). Roiser et al. have shown that the OM lipoprotein VacJ in Haemophilus influenzae and Vibrio cholerae influences OMV phospholipid content, while in A. baumannii OmpA influences the OMP composition and abundance in OMVs, though further investigation is required to elucidate the mechanism (Moon et al., 2012; Roier et al., 2016).

OMVs have long been hypothesized to function as a bacterial defense mechanism against the host innate immune system (Beceiro et al., 2013) due to their association with bacterial signaling, modulation of host-pathogen interactions and immune evasion. A. baumannii OMVs provide an important mechanism for the secretion of OmpA and other putative virulence factors to host cells, through interactions with eukaryotic cholesterol micro-domains (Kwon et al., 2009; Jin et al., 2011). In vivo OMVs can stimulate immune responses through the activation of TLR signaling or modulate immune evasion through sequestration of innate immune factors (Kaparakis-Liaskos and Ferrero, 2015). For example in E. coli, OMVs have been shown to be produced in response to treatment with antimicrobial peptides, while in $H$. influenzae and Moraxella catarrhalis, OMVs promote serum resistance through the depletion of complement factors (Thuan Tong et al., 2007; Manning and Kuehn, 2011; Roier et al., 2016). Furthermore, OMVs provide a unique opportunity for bacterial dissemination of encapsulated genetic material within communities or across species. Pseudomonas aeruginosa OMVs have been shown to contain DNA and RNA capable of modulating host immune responses (Koeppen et al., 2016; Bitto et al., 2017). Similarly, multiple groups have shown A. baumannii clinical isolates utilize OMVs as a mechanism for dissemination of plasmids containing carbapenem resistance genes, including $b l a_{\mathrm{OXA}-24}$ and $b l a_{\mathrm{NDM}-1}$ (Rumbo et al., 2011; Chatterjee et al., 2017), highlighting the versatility of this system and the requirement for more in-depth analysis.

\section{Nutrient Acquisition Metal Acquisition \\ Iron}

Iron is the most restricted nutrient in the human body. Bacteria have developed two scavenging mechanisms: direct uptake through receptors and transporters and high-affinity secreted iron chelator proteins (siderophores) (Eijkelkamp et al., 2011; De Léséleuc et al., 2014). A. baumannii strains encode up to five different siderophores. Cluster 1 comprises eight genes and a MFS family efflux pump, cluster 2 (only present in ATCC 17978) includes 15 genes with a separate MFS and MATE efflux pumps, cluster 3 is the well-characterized acinetobactin and $A B C$ efflux pump, while cluster 4 is only found in strain 8399, and cluster 5 is present in most strains with the exception of ATCC 17978 (Eijkelkamp et al., 2011). Despite cluster variability, those described to date are all transcriptionally regulated by Fur, identifiable by the presence 
of a Fur box sequence (a palindromic 25-nucleotide sequence) in their respective promoters (Eijkelkamp et al., 2011). In isolates, such as LAC-4 and SDF, the iron transporters and receptors FecI, FecR, and FecA are reported to enhance pathogenesis and growth capabilities of these strains through the utilization of heme (De Léséleuc et al., 2014).

Given the importance of iron-scavenging systems, it is unsurprising that disruption of these mechanisms causes dysregulation of other systems and virulence attenuation. In ATCC 17978, iron limitation results in a downregulation of Type 1 and Type IV pili (Eijkelkamp et al., 2011), while in ATCC 19606, disruption of the acinetobactin OM receptor, BauA, or the biosynthetic component, BasD, impairs intracellular persistence and killing of lung epithelial cells in vitro, though only varying degrees of attenuation are observed in G. mellonella and murine models (Gaddy et al., 2012). Similarly, disruption of Fur, iron-sulfur cluster assembly system (Isc), and/or other putative iron transporters (FeoA), leads to reduced bacterial biofilm formation, oxidative stress resistance, and in vivo pathogenesis (Ajiboye et al, 2018; Álvarez-Fraga et al., 2018). The phenotypes reported for fur mutants should be judged with caution due to the cross regulation with OxyR and SoxRS systems, which are associated with reactive oxygen detoxification and superoxide dismutase activation, and result in increased intracellular iron interacting with free radicals (Ajiboye et al., 2018). In contrast to that observed in the G. mellonella model, Fleming et al. reported that A. baumannii pathogenesis can be alleviated by the supply of excess iron to the surrounding environment when using a murine wound infection model, preventing the activation of iron-scavenging systems and virulence (Fleming et al., 2017).

\section{Zinc and Manganese}

Similar to iron, zinc is biologically important, acting as both a natural catalyst and cofactor for numerous proteins, with as many as $8 \%$ of E. coli-encoded proteins containing zinc-binding domains (Hood and Skaar, 2012). During the course of infection, the host can sequester metals by the action of the chelator protein calprotectin in a tactic termed "nutritional immunity" (Hood and Skaar, 2012; Nairn et al., 2016). A. baumannii regulates intracellular zinc concentrations by the activity of the ZnuABC transporter and ZigA GTPase, transcriptionally controlled by Zur (Mortensen et al., 2014; Nairn et al., 2016). While ZnuABC imports zinc into the cell, ZigA promotes its release through $\mathrm{HutH}$ activation and histidine catabolism (Mortensen et al., 2014; Nairn et al., 2016). This delicate balance between availability and toxicity results in a mild attenuation of $z i g A$ mutants in a murine pneumonia model, with less systemic dissemination from the lungs after infection (Nairn et al., 2016).

Although not characterized to the same degree, manganese starvation is of equal importance, whereby the NRAMP family transporter MumT and urea carboxylase, MumC, facilitate manganese accumulation in response to calprotectin (Juttukonda et al., 2016). Disruption of mumT significantly impacts bacterial colonization and dissemination from the lungs during pneumonia, a phenotype that is abolished in calprotectin-deficient mice
(Juttukonda et al., 2016), further emphasizing the interplay of host and bacterial proteins in pathogenesis.

\section{Community Interactions Quorum Sensing}

The ability of bacteria to sense, respond to, and communicate with neighboring cells is critical to the success of the population. Quorum sensing is the process by which bacteria detect and respond to hormone like molecules, such as acyl homoserine lactone, regulating numerous phenotypes, including motility and biofilm formation (Bhargava et al., 2010; Rutherford and Bassler, 2012). In the LuxRI family of proteins, LuxI synthesizes the acyl homoserine lactone, which interacts with the LuxR protein mediating the transcriptional response (Bhargava et al., 2010). In A. baumannii, abaI is responsible for the synthesis of N-(3-hydroxydodecanoyl)-L-HSL (3-hydroxy-C12-HSL), functioning in conjugation with the $a b a R$ LuxR homolog, to regulate biofilm maturation (Niu et al., 2008). Furthermore, the importance of this system in virulence has been demonstrated by the significant increase in murine survival rates during infection with abaI mutants (Bhuiyan et al., 2016).

\section{Biofilm Formation}

Biofilms are a bacterial lifestyle, constituting dynamic community environments, comprised of a heterogeneous protein matrix, nucleic acids, polysaccharides, and bacterial microcolonies, dispersed with water channels (Hall-Stoodley et al., 2004). A. baumannii forms biofilms on both biotic and abiotic surfaces, promoting survival on indwelling medical devices, hospital surfaces, or in otherwise unfavorable conditions. Biofilm formation is a multistage process, commencing with the initial attachment, proceeding to strong adhesion and aggregation of cells into microcolonies, followed by biofilm growth and maturation, prior to cell dispersal into the environment (Hall-Stoodley et al., 2004).

Biofilm formation on abiotic surfaces has contributed to the success of this pathogen in hospital environments, with their ability to adhere to medically relevant surfaces, such as titanium and polystyrene (Loehfelm et al., 2008; Brossard and Campagnari, 2011). Numerous strains encode for the Csu Type 1 chaperoneusher pili, associated with cell-to-cell attachment and biofilm initiation (Tomaras et al., 2008; Brossard and Campagnari, 2011). The operon contains six genes $\operatorname{csu} A / B, A, B, C, D$, and $E$, encoding for pili and minor subunits, the chaperone, the usher and adhesive tip, respectively (Moon et al., 2017). Despite being predominantly regulated by BfmRS TCS, the GacAS TCS also modulates its expression, in addition to a putative folate-responsive riboswitch identified in the $c s u$ and $b f m R$ promoters (Cerqueira et al., 2014; Moon et al., 2017), emphasizing the interplay between environmental signals and population dynamics. Despite BfmRS being predominantly associated with abiotic biofilms, this system is also linked to eukaryotic cell adhesion and antimicrobial resistance (Liou et al., 2014).

A. baumannii also produce the T1SS effector biofilm-associated protein, Bap, associated with abiotic and biotic biofilms. Homologous to that previously identified in Staphylococcus, it is defined by its immense size (over $800 \mathrm{kDa}$ ) and 
immunoglobulin-like fold (Loehfelm et al., 2008; Brossard and Campagnari, 2011). In contrast to Staphylococcus, A. baumannii Bap contains four modules, A-D, with numerous internal repeats, promoting cell-to-cell adhesion and eukaryotic cell adhesion, through modulation of cell surface hydrophobicity (Loehfelm et al., 2008; Brossard and Campagnari, 2011). Interestingly, despite their clearly defined roles in biofilm formation, numerous strains contain mutations which disrupt the $c s u$ operon or bap gene abolishing their production, though the significance of these findings has yet to be determined (Goh et al., 2013; Wright et al., 2016).

In addition to the Csu pilus, $A$. baumannii encodes a second shorter (29 $\mathrm{nm}$ in length) chaperone usher Pap pilus, homologous to that of E. coli $\mathrm{P}$ pilin that is associated with eukaryotic cell adhesion (De Breij et al., 2009; Marti et al., 2011; Cerqueira et al., 2014). In addition to pilus complexes, proteins such as the autotransporter Ata and the extracellular poly- $\beta-1,6-N$ acetylglucosamine (PNAG) encoded for by $p g a A B C D$ locus have also been shown to mediate attachment and adhesion of cells in the biofilm (Choi et al., 2009; Brossard and Campagnari, 2011).

\section{Genetic Regulation of Virulence Phenotypes}

\section{Transcriptional Regulation}

In addition to TCS, a recent study identified a Tet- $\mathrm{R}$ family transcription factor (encoded by $A B U W \_1645$ in strain AB5075) involved in the regulation of phenotypic switching between two colony types, termed opaque and translucent (Tipton et al., 2015; Chin et al., 2018). These morphological differences were not due to genetic mutations, and instead were driven by changes in the expression of $A B U W_{-} \_$1645, which regulates $\sim 70 \%$ of the differentially expressed genes including capsule biosynthesis (Chin et al., 2018). Interestingly, it is this phase variation and morphological difference that causes striking differences in in vivo pathogenesis, with the translucent form being avirulent, and frequent reversion to the opaque form is observed in cultures recovered from murine lungs post infection (Tipton et al., 2015; Chin et al., 2018). Consistent with this virulence phenotype, the opaque form shows resistance to cathelicidin-related antimicrobial peptides, reactive oxygen species (ROS), lysozyme, disinfectant, and desiccation. Thus, unsurprisingly, the opaque form is routinely isolated from clinical samples (Chin et al., 2018). The translucent form is thought to be associated with environmental settings and bacteriophage resistance, with its increased biofilm formation at lower temperatures, reduced capsule and upregulated nutrient acquisition and catabolism-related genes (Chin et al., 2018).

\section{$H-N S$}

The H-NS transcription factor is associated with silencing horizontally acquired and/or AT-rich genes, limiting their potentially detrimental effects (Eijkelkamp et al., 2013). Previous studies have shown disruption of hns in either ATCC 17978 or clinical isolates results in a myriad of phenotypes including hypermotility, increased colistin resistance, adhesion to epithelial cells, and in vivo virulence in Caenorhabditis elegans (Eijkelkamp et al., 2013; Deveson Lucas et al., 2018). Transcriptomic analysis of hns disruption mutants reveals a vast number of dysregulated genes, including the significant overexpression of those associated with quorum sensing, OMPs, T5SS, T6SS, and fatty acid biosynthesis (Eijkelkamp et al., 2013).

\section{Two-Component Regulatory Systems}

Two-component regulatory systems (TCSs) impact a diverse range of phenotypes by modulating transcriptional regulation. They are usually found as a pair of regulatory proteins, including a membrane-bound sensor kinase and a separate DNA-binding transcriptional regulator, which respond to environmental conditions and/or cell stress (Stock et al., 2000; Zschiedrich et al., 2016). To our knowledge, six TCSs have been described in A. baumannii, including BfmSR associated with morphology, biofilm formation and adhesion to eukaryotic cells (Tomaras et al., 2008; Liou et al., 2014), PmrAB, modulating lipid A modifications in response to antimicrobial peptides and polymyxin (Adams et al., 2009; Arroyo et al., 2011), BaeSR and AdeRS, which modulate the expression of the AdeABC efflux pump (Marchand et al., 2004; Lin et al., 2014), CheAY regulating the chaperone/usher pili and AbaI quorum sensing (Chen et al., 2017) and GacAS, associated with pathogenesis and host immune evasion (Cerqueira et al., 2014; Bhuiyan et al., 2016).

While all the TCSs play important roles in bacterial homeostasis and physiology, the GacAS system plays a critical role in bacterial pathogenesis and host-pathogen interactions. GacAS is a global regulator, whereby disruption of either gacA or gacS abolishes the ability of ATCC 17978 to cause lethality in either Candida albicans or murine models (Cerqueira et al., 2014). GacS forms the inner membrane sensor kinase, with conserved histidine and aspartic acid residues at $\mathrm{H} 299$ and D719/771, respectively, responsible for the phosphorylation of the transcriptional response regulator GacA (Cerqueira et al., 2014). Although GacAS regulates a variety of genes, including $o m p A, c s u$ operon, and $\operatorname{mot} B$ to name but a few, its role in the regulation of the phenylacetate catabolite pathway (paa operon) is a significant factor contributing to pathogenesis (Cerqueira et al., 2014). Inhibition of this pathway resulted in increased neutrophil migration to the site of infection and bacterial clearance (Cerqueira et al., 2014; Bhuiyan et al., 2016). It should be noted though, consistent with other previously described TCSs, GacAS does display some degree of cross regulation with others; however, paa transcriptional regulation is specific to GacAS.

\section{Post-transcriptional Regulation by Hfq}

The global RNA chaperone Hfq is an important regulator of bacterial virulence in a range of pathogens. In Salmonella and E. coli, $h f q$ mutations result in pleotropic effects, including reduced growth rates, changes in motility, biofilm formation, OMP levels, and attenuated in vivo virulence (Tsui et al., 1994; Bossi et al., 2008; Kulesus et al., 2008). Hfq can positively or negatively regulate messenger and/or small RNAs (sRNA) (Jousselin et al., 2009). Interestingly, Acinetobacter Hfq is almost double the size of that found in other gamma Proteobacteria, with an elongated $\mathrm{C}$ terminal, though the functional significance of this remains unknown (Kuo et al., 2017). Similar to other 
species, A. baylyi and A. baumannii hfq mutants display pleotropic phenotypes, including reduced growth rates, elevated sensitivity to environmental stress, reductions in OMV production, fimbriae, biofilm formation and adhesion, invasion and survival in eukaryotic cells (Schilling and Gerischer, 2009; Kuo et al., 2017). Furthermore, changes in cytokine stimulation have been reported with these mutants, though these effects are cell line specific (Kuo et al., 2017). Despite $h f q$ not being essential in ATCC 17978, this does not appear to be the case for all strains, as no $h f q$ transposon insertion mutant is available in the AB5075 library generated by Gallagher et al. (2015). These datasets highlight the critical need for further investigations into the role of these important and dynamic proteins in different strains in order to elucidate their roles and association with other accessory factors.

\section{IMMUNE RESPONSES}

\section{Innate Immune Response Cellular Immunity \\ Neutrophils}

The importance of neutrophils in response to A. baumannii was first noted regarding the increased prevalence of this pathogen in neutropenic patients. However, it was a further 10 years until Faassen and colleagues confirmed their importance in resistance to Acinetobacter respiratory infections (Van Faassen et al., 2007). Numerous in vivo studies show neutrophil recruitment to the site of infection occurs as early as $4 \mathrm{~h}$, peaking at $24 \mathrm{~h}$, and while their depletion results in enhanced lethality, this effect can be strain specific (Bruhn et al., 2015; Bhuiyan et al., 2016; García-Patiño et al., 2017). The recruitment and activation of neutrophils can be stimulated by a range of host factors, including cytokines and chemokines, though only the bacterial metabolic by-product phenylacetate has been shown to act as a bacterial-derived chemoattractant in the case of A. baumannii (Bhuiyan et al., 2016).

Neutrophils elicit antibacterial effects through phagocytosis, degranulation, and neutrophil extracellular trap (NETs) formation (Konstantinidis et al., 2016). Phagocytosis is mediated by TLR activation, IgG opsonization or complement-mediated receptor binding (Nordenfelt and Tapper, 2011). The process is extremely rapid, occurring in as little as $20 \mathrm{~s}$, through pseudopod and filopodia generation, with phagocytic arms capable of retaining and engulfing the bacteria (Nordenfelt and Tapper, 2011; LázaroDíez et al., 2017). Once phagocytosed, rapid killing is dependent on ROS and granular fusion, releasing a plethora of antimicrobial molecules, including human defensins and lysosome into the phagosome (Greenwald and Ganz, 1987; Borregaard and Cowland, 1997; Qiu et al., 2009; Nordenfelt and Tapper, 2011; Harding et al., 2017a). However, it is the capacity of neutrophils to kill A. baumannii that is contentious, with some in vitro studies reporting their co-culture does not affect the viability of either (Kamoshida et al., 2015, 2016). Instead, A. baumannii preferentially adhere to the neutrophil surface, in an IL-8dependent manner, promoting their dissemination (Kamoshida et al., 2016). While others have shown in vitro neutrophil phagocytosis kills $A$. baumannii, a finding consistent with in vivo studies (Lázaro-Díez et al., 2017). The reasoning behind such conflicting reports is most likely due to the experimental details, in that Kamoshida et al. tested only a single A. baumannii strain, ATCC 19606, at $1 \mathrm{~h}$ post infection, while Lázaro-Díez et al. performed an extensive assessment, testing 11 strains, including $5 \mathrm{~A}$. baumannii and $6 \mathrm{~A}$. pittii over a time course, emphasizing the importance of testing multiple strains.

NETs are an important mechanism by which neutrophils control pathogens, though their induction in response to $A$. baumannii is equally controversial (Brinkmann et al., 2004; Brinkmann and Zychlinsky, 2012; Kamoshida et al., 2015, 2018; Konstantinidis et al., 2016). NETs constitute a mesh of chromatin, impregnated with antimicrobial proteins and peptides, including myeloperoxidase, neutrophil elastase, and LL-37, respectively (Konstantinidis et al., 2016). NETs have been linked to the control of bacterial infections, while A. baumannii has been reported to inhibit their formation (Kamoshida et al., 2018). This mechanism of inhibition has yet to be fully elucidated and confirmed in vivo, though the neutrophil cell surface receptors $\mathrm{CD} 11 \mathrm{a}$ and $\mathrm{CD11b}$ have been implicated in the observed reduced adhesion of A. baumannii to neutrophils (Kamoshida et al., 2018).

While cytokines such as IL-8 and tumor necrosis factor (TNF)- $\alpha$ have stimulatory and chemoattractive effects on neutrophils, it should be noted that TNF- $\alpha$ induces concentration-dependent effects, including cytokine release and MAP kinase activation or cell apoptosis (March et al., 2010; Kikuchi-Ueda et al., 2017). Other host factors such as neutrophil phosphatase, Wip1, and serum amyloid A and $\mathrm{P}$ can also regulate neutrophil migration and pro-inflammatory cytokine secretion (Renckens et al., 2006; Sun et al., 2014).

\section{Macrophages}

Similar to neutrophils, the role of macrophages in A. baumannii infection is equally controversial. While their depletion in zebrafish has no effect, in murine models, macrophage depletion reduces pro-inflammatory cytokines and elevates bacterial burdens when depleted in conjunction with complement (Qiu et al., 2012; Bruhn et al., 2015; Bhuiyan et al., 2016). However, macrophages are important early defenders, promoting neutrophil recruitment and phagocytosis (Qiu et al., 2009, 2012). Alveolar macrophages provide the first line of defense against $A$. baumannii in the lungs, capable of microfilament and microtubule-dependent phagocytosis of the bacteria, stimulating high levels of IL-6, TNF- $\alpha$, and macrophage inflammatory protein-2, potent chemoattractants for neutrophils, with additional IL-1 $\beta$ and IL-10 produced at latter time points (Qiu et al., 2012). Though macrophages kill phagocytosed A. baumannii, they do so at a significantly slower rate than that of neutrophils; however, they can phagocytose bacteria in as little as $10 \mathrm{~min}$ (Qiu et al., 2012; Lázaro-Díez et al., 2017).

\section{Natural Killer Cells, Dendritic Cells, and Mast Cells}

Natural killer (NK) cells are an important defense against viral infections, intra- and extracellular bacteria; however, their role in A. baumannii infection remains largely unexplored (Small et al., 2008; Waggoner et al., 2016; Paidipally et al., 2018). 
In a murine pneumonia model, depletion of NK cells led to reduced survival and impaired bacterial clearance, though the impact of the NK cells was indirect, and mediated via the production of the neutrophil chemoattractant, keratinocyte chemoattractant (Tsuchiya et al., 2012). A. baumannii attachment to the natural cytotoxicity receptors on the surface of NK cells, has very low or no affinity, indicative that the interaction is indirect (Esin et al., 2008). Furthermore, NK cell cytotoxicity is significantly reduced in mice with A. baumannii septicaemia compared to uninfected controls; however, the mechanism defining this impact has not been explored (Cirioni et al., 2016).

Dendritic cells (DCs) are unique antigen-presenting cells linking the innate and adaptive immune systems. A. baumannii OmpA activates DCs in a dose-dependent manner, resulting in maturation, MAP kinase and NF- $\mathrm{KB}$ signaling, leading to the induction of a CD4+ $\mathrm{Th}_{1} \mathrm{~T}$ cell responses or early onset apoptosis and delayed necrosis (Lee et al., 2007). DC death is via mitochondrial targeting and production of ROS, consistent with OmpAs mechanism of action, suggestive that A. baumannii may modulate $\mathrm{T}$ cell response via this cell type (Lee et al., 2010). Furthermore, despite the identification of neutrophil-DC hybrids several years ago (Geng et al., 2013; Matsushima et al., 2013), it remains to be determined whether they contribute to the control of Acinetobacter infections.

Mast cells are considered sentinels of mucosal layers, sensing and responding to pathogen invasion. Lung mast cells have been shown to secrete IL- 8 and TNF- $\alpha$ in response to A. baumannii, enhancing neutrophil recruitment to the site (Kikuchi-Ueda et al., 2017).

\section{Cell Signaling in Response to Acinetobacter Toll-Like Receptor Signaling}

Toll-like receptor (TLR) signaling is an important mechanism by which hosts recognize and respond to pathogens. Of the 11 reported TLRs, TLR2, 4, and 9 are critical for the recognition and response to $A$. baumannii, through the detection of lipoproteins, peptidoglycan, porins, lipoteichoic acid (TLR2), LOS (TLR4), and unmethylated CpG DNA motifs (TLR9) (Knapp et al., 2006; Lin et al., 2012; Moffatt et al., 2013; Noto et al., 2015).

Host signaling via TLR2 and 4 has been extensively documented, whereby activation of either receptor, in the presence or absence of the soluble GPI-linked glycoprotein, $\mathrm{CD} 14$, leads to NF- $\mathrm{KB}$ activation in a MyD88-dependent fashion, resulting in the secretion of pro-inflammatory cytokines including TNF- $\alpha$; IFN- $\gamma$; IL-1, 6, 8, 10, and 12 (Lin et al., 2012; Moffatt et al., 2013; García-Patiño et al., 2017). TLR2 is important for DC recognition of $A$. baumannii OmpA; however, there are conflicting reports regarding the impact of TLR2 knockout, whereby Kim et al. reported increased bacterial burdens in the first $24 \mathrm{~h}$ of infection in TLR2 -/- mice, while Knapp et al. observed significantly lower bacterial burdens at the same time point (Knapp et al., 2006; Kim et al., 2014; García-Patiño et al., 2017). These differences may be attributed to the use of different A. baumannii isolates, though further investigation is clearly warranted. By contrast, TLR4 -/- and/or CD14 -/both result in increased bacterial burdens in pneumonia models, as a result of reduced pro-inflammatory cytokine responses and neutrophil recruitment. Interestingly though, TLR4 knockout has also been shown to reduce the lethality of $A$. baumannii septicaemia, by limiting septic shock caused by LOS (Lin et al., 2012). Consistent with this finding, A. baumannii virulence has also been linked to the levels of LOS shedding and TLR4 signaling (Lin et al., 2012). Similarly, the treatment of A. baumannii-infected animals with LpxC inhibitors protects against lethality, by enhancing TLR2 stimulation and reducing NF-кB signaling and TNF- $\alpha$ secretion by four- and two-fold respectively, promoting opsonophagocytic killing in response to increased surface PNAG (Lin et al., 2012; Moffatt et al., 2013). By contrast, A. baumannii isolates with phosphoethalomine-modified lipid A induce significantly higher levels of TLR4 signaling compared to unmodified LOS (Lin et al., 2012).

In contrast to TLR2 and TLR4, TLR9 signaling in response to A. baumannii is the least well characterized. TLR9 is an internal receptor of the endolysosome, responsible for the detection of bacterial and viral DNA (Noto et al., 2015; Harding et al., 2017a). Similarly, its stimulation promotes NF-кB activation and pro-inflammatory cytokine responses, whereby TLR9 -/mice have reduced TNF- $\alpha$ and IFN- $\Upsilon$ in response to A. baumannii lung infections, causing elevated bacterial burdens, systemic dissemination, and increased tissue damage (Noto et al., 2015).

\section{Soluble Secreted Factors}

The production of pro-inflammatory cytokines in response to A. baumannii is primarily via NF- $\mathrm{KB}$ activation, with each cytokine driving a different response. For example, NLRP3caspase 1 - caspase 11 activation leads to the release of IL-1 $\beta$ and IL-18 from infected lung epithelia resulting in tissue damage (Dikshit et al., 2017). IL-17, however, promotes granulocytopoiesis and drives secretion of GM-CSF and IL-8, stimulating the antimicrobial peptide LL-37 (García-Patiño et al., 2017). With the release of IL- 8 and TNF- $\alpha$, neutrophils are recruited and activated (March et al., 2010; Bist et al., 2014). However, while IL-33 represses IL-8 secretion, it is known to also promote neutrophil migration and stimulation (Peng et al., 2018).

Epithelial cells and neutrophils also secrete an array of antimicrobial peptides, including human $\beta$-defensin 2 and 3, the cathelicidin LL-37 and CD14 enhancing TLR4 ligand interactions through myeloid differentiation factor 2 binding (March et al., 2010; García-Patiño et al., 2017; Harding et al., 2017a). A. baumannii is highly susceptible to human $\beta$-defensin 2 , which causes membrane disruption and increased permeability, although the potential for cell death via non-membrane lytic methods (i.e., inhibition of nucleic acid synthesis) or synergy with other antimicrobial peptides cannot be excluded (Cobo and Chadee, 2013). Interestingly, only LOS-deficient A. baumannii demonstrates elevated sensitivity to the antimicrobial peptide LL-37, despite the target considered to be LOS (Moffatt et al., 2013).

\section{Intracellular Responses}

Despite A. baumannii being considered an extracellular pathogen, in vitro evidence exists for their ability to invade lung epithelial cells and macrophages (Choi et al., 2008b; Qiu et al., 2012), 
though this observation is controversial, and the evidence should be viewed with caution, given the limitations of the studies. In both instances, only a single A. baumannii strain was tested, with extracellular bacteria eliminated using gentamicin; however, the authors neglect to provide either the minimum inhibitory concentration for their respective strains or suitable microscopy to support their observations. In contrast to these reports, other studies testing a range of $A$. baumannii strains have been unable to visualize a direct interaction or invasion of the lung epithelial cell line A549, irrespective of MOI or incubation duration (Lázaro-Díez et al., 2016). Furthermore, Qiu et al. observed a reduction in bacterial viability during co-culture with macrophages (Qiu et al., 2012), suggesting that these observations are purely phagocytosis as opposed to active invasion and their significance in the context of in vivo infection has yet to be confirmed.

In addition to TLR9, the cytosolic family of NOD-like receptors, including Nod1 and Nod2 associated with pathogenassociated molecular pattern recognition, induce NF- $\mathrm{B}$, but not MAP kinase through interactions with Rip2 (Bist et al., 2014). This NF-кB activation induces IL-8, TNF- $\alpha$ and $\beta$-defensin, although it should be noted these responses are cell type specific (Bist et al., 2014). ROS and nitric oxide play critical and moderate roles in the control of intracellular A. baumannii, respectively (Qiu et al., 2009, 2012). Evident by the fact that gp91 ${ }^{\text {phox }}-/-$ mice, deficient in the NADPH phagosomal oxidase (and thus ROS), are more susceptible to A. baumannii infection than neutropenic mice, while those defective for nitric oxide production demonstrate only moderate increases in bacterial burdens (Qiu et al., 2009).

\section{Complement-Mediated Killing}

Complement-mediated killing is an important non-cellular innate immune component, consisting of multiple soluble factors, acting in a cascade promoting either bacterial cell lysis or opsonophagocytosis. Three pathways exist for the deposition of complement factors on to bacterial surfaces, although in human serum, the alternative complement pathway is required for A. baumannii killing (Garcia et al., 2000; Kim et al., 2009; King et al., 2009; Bruhn et al., 2015). Resistance is frequently reported in clinical A. baumannii isolates and in vitro serum resistance may correlate with more severe disease (Bruhn et al., 2015).

The alternative complement pathway is regulated by factor $\mathrm{H}$, a soluble component important for the recognition of host cell markers (Ferreira et al., 2010). Activation of the alternative complement pathway leads to the deposition of C3 on the surface of serum-sensitive isolates, though discrepancies exist surrounding the binding of factor $\mathrm{H}$ to bacterial cells and subsequent inhibition of C3 deposition, promoting serum resistance in A. baumannii (Dave et al., 2001; King et al., 2009; Laarman et al., 2011). Previously, Kim et al. reported that factor $\mathrm{H}$ bound to $A$. baumannii OMPs, promoting serum resistance (Kim et al., 2009). While King et al. were unable to identify bound factor $\mathrm{H}$ on their serum-resistant isolates (King et al., 2009), suggesting that factor $\mathrm{H}$ acquisition is not solely responsible.

Furthermore, the A. baumannii plasminogen-binding protein, CipA, was also shown to inhibit the alternative complement pathway via $\mathrm{C} 3 \mathrm{~b}$ cleavage and degradation of fibrin networks, by mechanisms that have yet to be fully elucidated (Koenigs et al., 2016). Consistent with the role of CipA in complement resistance, cipA deletion mutants are also more susceptible to killing by human serum (King et al., 2013).

Genes involved in A. baumannii cell envelope homeostasis also contribute to serum resistance. For example, disruption of the TCS $b f m S$, which regulates pilus and capsule biosynthesis, leads to serum resistance (Geisinger et al., 2018). A. baumannii genes associated with capsule biosynthesis and glycosylation, including $p t k$, eps $A, m l t B$, and $p g l C$, encoding a putative tyrosine kinase, OM polysaccharide exporter, lytic transglycosylase and glycosyltransferase, respectively, are required for resistance to killing in human ascites fluid and serum, highlighting the importance of capsule in resisting complement (Russo et al., 2010; Lees-Miller et al., 2013; Crépin et al., 2018).

\section{Adaptive Immune Response}

While numerous studies have examined the ability of different bacterial components to induce a range of adaptive immune responses (McConnell and Pachón, 2010; McConnell et al., 2011a,b; García-Quintanilla et al., 2014; Badmasti et al., 2015; Kuolee et al., 2015; Garg et al., 2016; Ainsworth et al., 2017; Bazmara et al., 2017; Pulido et al., 2018; Song et al., 2018), very little work has been done to examine these during the course of infection, due to several confounding factors, including the available animal models, rate of disease progression and severity.

To our knowledge, the importance of $\mathrm{Th}_{1}$ vs. $\mathrm{Th}_{2}$ or $\mathrm{Th}_{17}$ responses has yet to be fully elucidated with regard to A. baumannii infection. Despite IL-17 being important for neutrophil recruitment and secretion of $\beta$-defensin, deletion of IL-17A in mice has no impact on bacterial burdens (Breslow et al., 2011; Yan et al., 2016). Furthermore, Qui et al. demonstrated that mice which recover from sub-lethal infections do not have increased survival compared to naïve mice when infected with a lethal dose of $A$. baumannii 6 weeks later, despite having significantly higher levels of CD4+ and CD8a+ T cells and CD19+ B lymphocytes (Qiu et al., 2016). This suggests that adaptive immune responses play only a minor role in the resolution of A. baumannii infections. By contrast, some studies have shown the induction of antibody subtypes, IgM and IgG (isotypes IgG1 and 2c), and cytokines, IFN- $\Upsilon$, IL-4, and IL-17, can promote bacterial killing and improve host survival (McConnell et al., 2011b; Luo et al., 2012; García-Quintanilla et al., 2014). Further work is needed to clarify the significance of different adaptive immune components in the clearance of and resistance to A. baumannii infections.

\section{IN VIVO MODELS FOR THE STUDY OF A. BAUMANNII HOST-PATHOGEN INTERACTIONS}

\section{Mammalian Models}

Murine models have been the predominant mammalian model used to study Acinetobacter infections over the last 30 years, 
with a small number of studies also utilizing rabbits (RodríguezHernández et al., 2004; Pachón-Ibáñez et al., 2010) and guinea pigs (Bernabeu-Wittel et al., 2005). While initial studies focused on assessing antibiotic efficacy, more recent studies have investigated bacterial pathogenesis, host interactions, immunity and alternative therapeutic treatments (Obana et al., 1985; Joly-Guillou et al., 1997; Ko et al., 2004; Knapp et al., 2006; Jacobs et al., 2010; Cerqueira et al., 2014; Lood et al., 2015; Noto et al., 2015; Sebe et al., 2016; Dikshit et al., 2017; Murray et al., 2017; Peng et al., 2017). A number of models have been developed for skin and soft tissue infection, endocarditis, osteomyelitis, bloodstream infection, and pneumonia, with the latter two being the most commonly used given the frequency and severity of these infections in hospital and community settings (Peleg et al., 2008a; McConnell et al., 2013).

\section{Bloodstream Infection}

Several bacterial virulence factors have been confirmed using bloodstream infection models, including the acinetobactin iron acquisition system, the universal stress protein A (UspA), and the TCS GacAS (Gaddy et al., 2012; Cerqueira et al., 2014; Elhosseiny et al., 2015). A recent investigation utilized a bacteremia model to determine the global gene expression profile of A. baumannii ATCC 17978 during a life-threatening infection, and compared expression profiles between in vitro and in vivo growth, revealing 886 differentially expressed genes (Murray et al., 2017).

Recently, bloodstream infection models have been expanded to test the efficacy of bacteriophage therapy to treat lethal infections. Lood et al. used purified, recombinant autolysin from a bacteriophage to treat mice infected with a lethal dose of A. baumannii, resulting in increased survival in lysin-treated mice (up to 50\%) and reduced A. baumannii burdens (Lood et al., 2015). Similar results were observed with a more recent study using another bacteriophage lysin (Peng et al., 2017).

\section{Pneumonia}

Lung infection models were first used in 1997 to evaluate the efficacy of imipenem in vivo against acute A. baumannii pneumonia (Joly-Guillou et al., 1997). Two lung infection methods are most commonly used to induce pneumonia in mice: intra-tracheal, where the trachea of an anesthetized mouse is cannulated with a blunt-ended needle and the inoculum instilled; or intranasal, where the inoculum is pipetted over the nares of anesthetized mice (Joly-Guillou et al., 1997; Eveillard et al., 2010). Both methods induce inflammatory and histological responses consistent with acute pneumonia and a number of virulence factors have been assessed using these models, including phospholipase $\mathrm{D}, \mathrm{OmpA}$, and a heme oxygenase (Choi et al., 2008b; Jacobs et al., 2010; De Léséleuc et al., 2014). Assessment of essential A. baumannii genes in the context of pneumonia has also been performed using a transposon mutant library of A. baumannii ATCC 17978 and comparing input and output mutant pools after lung infection (Wang et al., 2014). This approach identified 157 genes, including OmpA and several novel virulence factors that are required for a pneumonia infection.
Over the last 15 years, mouse pneumonia models have been increasingly used to understand the host immune response to A. baumannii as described above. Furthermore, vaccine efficacy studies have now also been performed using mouse infection models. (McConnell and Pachón, 2010; McConnell et al., 2011a; Luo et al., 2012; Russo et al., 2013; Qiu et al., 2016).

With the rise in studies, it is also now recognized that different strains of A. baumannii elicit different immune responses in mice (De Breij et al., 2012; Dikshit et al., 2017). This is an important finding considering that for many years, strains such as ATCC 17978 and 19606 have been used to study A. baumannii pathogenesis; however, they are not representative of the dominant clinical strains found in hospitals today. When compared to international clonal Type I and II strains, they have reduced virulence and elicit different immune responses (Eveillard et al., 2010; De Breij et al., 2012; Dikshit et al., 2017).

\section{Other Infection Models}

As previously described, a number of other infection models exist for studying A. baumannii infections. Skin and soft tissue models have been developed in both mice and rats for treatment studies and as a screening tool for determining gene essentiality (Shankar et al., 2007; Russo et al., 2008; Dai et al., 2009). Several groups have tried to develop an osteomyelitis model in mice and rats with varying levels of success (Crane et al., 2009; Collinet-Adler et al., 2011). Crane et al. were able to establish a non-lethal infection in mice by implanting stainless steel pins into their tibias, while Collinet-Adler et al. were unable to establish chronic bone infections in rats (Crane et al., 2009; Collinet-Adler et al., 2011). Rabbits have been used for studying meningitis and endocarditis, and guinea pigs used to study pneumonia (Rodríguez-Hernández et al., 2004; Bernabeu-Wittel et al., 2005; Pachón-Ibáñez et al., 2010). While larger animals allow researchers to sample the same animal at multiple time points, the increased costs and ethical concerns associated with larger animals have limited their use thus far.

The increasing costs and growing ethical concerns regarding mammalian models have spurred the development of non-mammalian models such as C. elegans, G. mellonella, and zebrafish for studying A. baumannii host-pathogen interactions. Despite their clear differences from mice and humans, non-mammalian models have proved useful for the assessment of mutants, screening compounds, and enabling visualization of host-pathogen interactions.

\section{Caenorhabditis elegans}

C. elegans, a small soil-dwelling nematode was the first non-mammalian model to be used to study $A$. baumannii pathogenesis (Smith et al., 2004). The small size (1 mm), transparency, short replication cycle (2-3 days), and wellcharacterized genome make it an ideal model to study bacterialhost interactions. It was first used by Smith et al. to study A. baumannii pathogenesis in the presence of ethanol, with a later method developed using proliferation and brood size as the outcome measure rather than worm death (Smith et al., 2004, 2007). 
Polymicrobial interactions between A. baumannii and Candida albicans have also been assessed in C. elegans, where A. baumannii reduced $C$. albicans filament production and virulence within the worm (Peleg et al., 2008b). C. elegans has most recently been used to screen potential antimicrobial agents (Jayamani et al., 2015; Mohamed et al., 2017). Jayamani et al. used a liquid infection assay in a 384-well format to concurrently assess the antimicrobial activity of peptides in parallel to evaluating host toxicity, revealing 15 molecules that prolonged worm survival (Jayamani et al., 2015). A disadvantage of C. elegans though is their requirement to be maintained at $25^{\circ} \mathrm{C}$, with $37^{\circ} \mathrm{C}$ causing worm death. This may impact the virulence of pathogens including A. baumannii (Peleg et al., 2009; De Silva et al., 2017).

\section{Galleria mellonella}

G. mellonella (caterpillars of the greater wax moth) have a considerable advantage over $C$. elegans in that they can be maintained at $37^{\circ} \mathrm{C}$ and a precise inoculum or therapeutic dose can be administered into the body of the caterpillar (Peleg et al., 2009; Hornsey et al., 2013). G. mellonella also have a more advanced immune system with both humoral and phagocytic cells (Peleg et al., 2009). A. baumannii kills G. mellonella in a dose-dependent manner and survival can be prolonged by the administration of antibiotics (Peleg et al., 2009). G. mellonella has since been used to test the efficacy of antibiotic combinations, assess the virulence of mutants, or compare pathogenicity between strains (Peleg et al., 2009; Antunes et al., 2011; Hornsey and Wareham, 2011; Gaddy et al., 2012; Iwashkiw et al., 2012; Wand et al., 2012; Hornsey et al., 2013; O'Hara et al., 2013; Yang et al., 2015; Betts et al., 2017). A disadvantage of note is that G. mellonella sourced from different suppliers can show significant variance in results (Betts et al., 2017). However, with their increasing use, more standardized models have been developed that control for age, size, and food supply.

\section{Dictyostelium discoideum}

D. discoideum is a unicellular amoeba that feeds on bacteria, with previous work having highlighted similarities between amoeba phagocytosis and mammalian immune cell phagocytosis (Hasselbring et al., 2011). It has therefore been proposed that when used in conjunction with other non-mammalian models, such as C. elegans, which kill via extracellular methods, the two can represent multiple areas of a mammalian infection (Smith et al., 2007). In order to determine whether bacteria are killed by $D$. discoideum, liquid cultures of the two are mixed and plated, allowing the faster growing bacteria to form a lawn, with formation of plaques if amoeba are able to phagocytose bacteria (Smith et al., 2007; Iwashkiw et al., 2012; Weber et al., 2013). D. discoideum and C. elegans have been jointly used to screen transposon mutant libraries for attenuated mutants (Smith et al., 2007). Two other studies were performed using D. discoideum and C. elegans and showed that the T6SS is not required for virulence, while a glycosylation pathway was (Iwashkiw et al., 2012; Weber et al., 2013).

\section{Zebrafish}

Zebrafish (Danio rerio) are the most recent non-mammalian model to be utilized for host-pathogen interaction studies. Zebrafish are a small $(3-4 \mathrm{~cm})$ freshwater fish native to India, Pakistan, and Bhutan and are susceptible to a range of bacteria, including Vibrio cholera, S. aureus, and Shigella flexneri (Prajsnar et al., 2008; Mostowy et al., 2013; Runft et al., 2014). A considerable advantage of zebrafish to other non-mammalian models is their advanced immune system development with innate immune cells present at $25 \mathrm{~h}$ post fertilization and a fully functional adaptive immune system developed by adulthood (Van Der Sar et al., 2004). Transparency can be maintained to allow for real-time visualization, numerous transgenic fish lines are available, including fluorescently tagged neutrophils and macrophages and immune cell-depleted fish (Hall et al., 2007; White et al., 2008; Ellett et al., 2010; Li et al., 2010). The establishment of zebrafish to study A. baumannii pathogenesis has recently been published, and showed that $A$. baumannii is lethal toward zebrafish in a dose-dependent manner, with interactions between $A$. baumannii and neutrophils easily imaged (Bhuiyan et al., 2016). The unique advantages of real-time imaging during infection allowed the authors to elucidate novel findings related to neutrophil migration in the context of an A. baumannii infection.

\section{CONCLUSIONS}

Taken together, this review highlights the real advances that have been made in our understanding of $A$. baumannii pathogenesis, but further highlights areas in need of more in-depth analysis. Consistency and transparency in the field and subsequent publications will optimize the success of future studies. The selection of multiple and appropriate A. baumannii strains, encompassing those that are representative of modern-day clinical isolates and human infections, combined with the standardization of cell lines, animal models, and procedures will provide a level of uniformity across all studies. Such consistency will not only enable direct comparison between studies, but also advance our overall understanding of this important pathogen.

However, the future does hold promise with more innovative techniques and the rapid advancement of technology, new approaches are providing greater insight into the intricacies of regulatory networks not only in the bacterial cell but also in the host. As cross-disciplinary research continues to grow, so too does our understanding of this important pathogen and its hosts.

\section{AUTHOR CONTRIBUTIONS}

CD wrote the "In vivo models" section and the "Introduction". XK wrote the "Natural Killer Cells, Dendritic Cells, and Mast Cells" section. MU wrote the section "Neutrophils". FM wrote all remaining sections and prepared the figures. AP edited the manuscript. 


\section{REFERENCES}

Adams, M. D., Nickel, G. C., Bajaksouzian, S., Lavender, H., Murthy, A. R., Jacobs, M. R., et al. (2009). Resistance to colistin in Acinetobacter baumannii associated with mutations in the PmrAB two-component system. Antimicrob. Agents Chemother. 53, 3628-3634. doi: 10.1128/AAC.00284-09

Ahmad, T. A., Tawfik, D. M., Sheweita, S. A., Haroun, M., and El-Sayed, L. H. (2016). Development of immunization trials against Acinetobacter baumannii. Trials Vaccinol. 5, 53-60. doi: 10.1016/j.trivac.2016.03.001

Ainsworth, S., Ketter, P. M., Yu, J.-J., Grimm, R. C., May, H. C., Cap, A. P., et al. (2017). Vaccination with a live attenuated Acinetobacter baumannii deficient in thioredoxin provides protection against systemic Acinetobacter infection. Vaccine 35, 3387-3394. doi: 10.1016/j.vaccine.2017.05.017

Ajiboye, T. O., Skiebe, E., and Wilharm, G. (2018). Contributions of ferric uptake regulator fur to the sensitivity and oxidative response of Acinetobacter baumannii to antibiotics. Microb. Pathog. 119, 35-41. doi: 10.1016/j.micpath.2018.03.060

Álvarez-Fraga, L., Vázquez-Ucha, J. C., Martínez-Guitián, M., Vallejo, J. A., Bou, G., Beceiro, A., et al. (2018). Pneumonia infection in mice reveals the involvement of the $f e o A$ gene in the pathogenesis of Acinetobacter baumannii. Virulence 9, 496-509. doi: 10.1080/21505594.2017.1420451

Ansari, H., Doosti, A., Kargar, M., Bijanzadeh, M., and Jaafarinia, M. (2018). Cloning of ompA gene from Acinetobacter baumannii into the eukaryotic expression vector pBudCE4.1 as DNA vaccine. Indian J. Microbiol. 58, 174-181. doi: 10.1007/s12088-017-0705-x

Anstey, N. M., Currie, B. J., and Withnall, K. M. (1992). Community-acquired Acinetobacter pneumonia in the northern territory of Australia. Clin. Infect. Dis. 14, 83-91. doi: 10.1093/clinids/14.1.83

Antunes, L. C. S., Imperi, F., Carattoli, A., and Visca, P. (2011). Deciphering the multifactorial nature of Acinetobacter baumannii pathogenicity. PLoS One 6:e22674. doi: 10.1371/journal.pone.0022674

Antunes, L. C. S., Visca, P., and Towner, K. J. (2014). Acinetobacter baumannii: evolution of a global pathogen. Pathog. Dis. 71, 292-301. doi: 10.1111/2049-632X.12125

Arroyo, L. A., Herrera, C. M., Fernandez, L., Hankins, J. V., Trent, M. S., and Hancock, R. E. W. (2011). The pmrCAB operon mediates polymyxin resistance in Acinetobacter baumannii ATCC 17978 and clinical isolates through phosphoethanolamine modification of lipid A. Antimicrob. Agents Chemother. 55, 3743-3751. doi: 10.1128/AAC.00256-11

Badmasti, F., Ajdary, S., Bouzari, S., Fooladi, A. A. I., Shahcheraghi, F., and Siadat, S. D. (2015). Immunological evaluation of OMV(PagL)+Bap(1-487aa) and $\mathrm{AbOmpA}(8-346 \mathrm{a})+\mathrm{Bap}(1-487 \mathrm{aa})$ as vaccine candidates against Acinetobacter baumannii sepsis infection. Mol. Immunol. 67, 552-558. doi: 10.1016/j.molimm.2015.07.031

Bazmara, H., Rasooli, I., Jahangiri, A., Sefid, F., Astaneh, S. D. A., and Payandeh, Z. (2017). Antigenic properties of iron regulated proteins in Acinetobacter baumannii: an in silico approach. Int. J. Pept. Res. Ther. 25, 205-213. doi: 10.1007/s10989-017-9665-6

Beceiro, A., Tomás, M., and Bou, G. (2013). Antimicrobial resistance and virulence: a successful or deleterious association in the bacterial world? Clin. Microbiol. Rev. 26, 185-230. doi: 10.1128/CMR.00059-12

Bentancor, L. V., Camacho-Peiro, A., Bozkurt-Guzel, C., Pier, G. B., and Maira-Litrán, T. (2012a). Identification of Ata, a multifunctional trimeric autotransporter of Acinetobacter baumannii. J. Bacteriol. 194, 3950-3960. doi: 10.1128/JB.06769-11

Bentancor, L. V., Routray, A., Bozkurt-Guzel, C., Camacho-Peiro, A., Pier, G. B., and Maira-Litrán, T. (2012b). Evaluation of the trimeric autotransporter Ata, as a vaccine candidate against Acinetobacter baumannii infections. Infect. Immun. 80, 3387-3388. doi: 10.1128/IAI.06096-11

Bernabeu-Wittel, M., Pichardo, C., García-Curiel, A., Pachón-Ibáñez, M. E., Ibáñez-Martínez, J., Jiménez-Mejías, M. E., et al. (2005). Pharmacokinetic/ pharmacodynamic assessment of the in-vivo efficacy of imipenem alone or in combination with amikacin for the treatment of experimental multiresistant Acinetobacter baumannii pneumonia. Clin. Microbiol. Infect. 11, 319-325. doi: 10.1111/j.1469-0691.2005.01095.x

Betts, J. W., Hornsey, M., Wareham, D. W., and La Ragione, R. M. (2017). In vitro and In vivo activity of theaflavin-epicatechin combinations versus multidrug-resistant Acinetobacter baumannii. Infect. Dis. Ther. 6, 435-442. doi: $10.1007 / s 40121-017-0161-2$
Bhargava, N., Sharma, P., and Capalash, N. (2010). Quorum sensing in Acinetobacter: an emerging pathogen. Crit. Rev. Microbiol. 36, 349-360. doi: 10.3109/1040841X.2010.512269

Bhuiyan, M. S., Ellett, F., Murray, G. L., Kostoulias, X., Cerqueira, G. M., Schulze, K. E., et al. (2016). Acinetobacter baumannii phenylacetic acid metabolism influences infection outcome through a direct effect on neutrophil chemotaxis. Proc. Natl. Acad. Sci. 113, 9599-9604. doi: 10.1073/pnas. 1523116113

Bist, P., Dikshit, N., Koh, T. H., Mortellaro, A., Tan, T. T., and Sukumaran, B. (2014). The Nod1, Nod2, and Rip2 axis contributes to host immune defense against intracellular Acinetobacter baumannii infection. Infect. Immun. 82, 1112-1122. doi: 10.1128/IAI.01459-13

Bitto, N. J., Chapman, R., Pidot, S., Costin, A., Lo, C., Choi, J., et al. (2017). Bacterial membrane vesicles transport their DNA cargo into host cells. Sci. Rep. 7:7072. doi: 10.1038/s41598-017-07288-4

Boll, J. M., Crofts, A. A., Peters, K., Cattoir, V., Vollmer, W., Davies, B. W., et al. (2016). A penicillin-binding protein inhibits selection of colistin-resistant lipooligosaccharide-deficient Acinetobacter baumannii. Proc. Natl. Acad. Sci. 113, E6228-E6237. doi: 10.1073/pnas.1611594113

Boll, J. M., Tucker, A. T., Klein, D. R., Beltran, A. M., Brodbelt, J. S., Davies, B. W., et al. (2015). Reinforcing lipid A acylation on the cell surface of Acinetobacter baumannii promotes cationic antimicrobial peptide resistance and desiccation survival. MBio 6, e00478-e00415. doi: 10.1128/mBio.00478-15

Borregaard, N., and Cowland, J. B. (1997). Granules of the human neutrophilic polymorphonuclear leukocyte. Blood 89, 3503-3521.

Bossi, L., Maloriol, D., and Figueroa-Bossi, N. (2008). Porin biogenesis activates the sigma E response in Salmonella hfq mutants. Biochimie 90, 1539-1544. doi: 10.1016/j.biochi.2008.06.001

Breslow, J. M., Meissler, J. J., Hartzell, R. R., Spence, P. B., Truant, A., Gaughan, J., et al. (2011). Innate immune responses to systemic Acinetobacter baumannii infection in mice: neutrophils, but not Interleukin-17, mediate host resistance. Infect. Immun. 79, 3317-3327. doi: 10.1128/IAI.00069-11

Brinkmann, V., Reichard, U., Goosmann, C., Fauler, B., Uhlemann, Y., Weiss, D. S., et al. (2004). Neutrophil extracellular traps kill bacteria. Science 303, 1532-1535. doi: 10.1126/science.1092385

Brinkmann, V., and Zychlinsky, A. (2012). Neutrophil extracellular traps: is immunity the second function of chromatin? J. Cell Biol. 198, 773-783. doi: $10.1083 /$ jcb.201203170

Brossard, K. A., and Campagnari, A. A. (2011). The Acinetobacter baumannii biofilm associated protein (Bap) plays a role in adherence to human epithelial cells. Infect. Immun. 80, 228-233. doi: 10.1128/IAI.05913-11

Bruhn, K. W., Pantapalangkoor, P., Nielsen, T., Tan, B., Junus, J., Hujer, K. M., et al. (2015). Host fate is rapidly determined by innate effector-microbial interactions during Acinetobacter baumannii bacteremia. J. Infect. Dis. 211, 1296-1305. doi: 10.1093/infdis/jiu593

Cahill, B. K., Seeley, K. W., Gutel, D., and Ellis, T. N. (2015). Klebsiella pneumoniae $\mathrm{O}$ antigen loss alters the outer membrane protein composition and the selective packaging of proteins into secreted outer membrane vesicles. Microbiol. Res. 180, 1-10. doi: 10.1016/j.micres.2015.06.012

Cerqueira, G. M., Kostoulias, X., Khoo, C., Aibinu, I., Qu, Y., Traven, A., et al. (2014). A global virulence regulator in Acinetobacter baumannii and its control of the phenylacetic acid catabolic pathway. J. Infect. Dis. 210, 46-55. doi: 10.1093/infdis/jiu024

Chatterjee, S., Mondal, A., Mitra, S., and Basu, S. (2017). Acinetobacter baumannii transfers the blaNDM-1 gene via outer membrane vesicles. J. Antimicrob. Chemother. 72, 2201-2207. doi: 10.1093/jac/dkx131

Chen, R., Lv, R., Xiao, L., Wang, M., Du, Z., Tan, Y., et al. (2017). A1S_2811, a CheA/Y-like hybrid two-component regulator from Acinetobacter baumannii ATCC17978, is involved in surface motility and biofilm formation in this bacterium. MicrobiologyOpen 6:e00510. doi: 10.1002/mbo3.510

Chin, C. Y., Tipton, K. A., Farokhyfar, M., Burd, E. M., Weiss, D. S., and Rather, P. N. (2018). A high-frequency phenotypic switch links bacterial virulence and environmental survival in Acinetobacter baumannii. Nat. Microbiol. 3, 563-569. doi: 10.1038/s41564-018-0151-5

Choi, C. H., Hyun, S. H., Kim, J., Lee, Y. C., Seol, S. Y., Cho, D. T., et al. (2008a). Nuclear translocation and DNAse I-like enzymatic activity of Acinetobacter baumannii outer membrane protein A. FEMS Microbiol. Lett. 288, 62-67. doi: 10.1111/j.1574-6968.2008.01323.x 
Choi, C. H., Lee, J. S., Lee, Y. C., Park, T. I., and Lee, J. C. (2008b). Acinetobacter baumannii invades epithelial cells and outer membrane protein A mediates interactions with epithelial cells. BMC Microbiol. 8:216. doi: 10.1186/14712180-8-216

Choi, A. H. K., Slamti, L., Avci, F. Y., Pier, G. B., and Maira-Litrán, T. (2009). The pgaABCD locus of Acinetobacter baumannii encodes the production of poly- $\beta-1-6-\mathrm{N}$-acetylglucosamine, which is critical for biofilm formation. J. Bacteriol. 191, 5953-5963. doi: 10.1128/JB.00647-09

Cirioni, O., Simonetti, O., Pierpaoli, E., Barucca, A., Ghiselli, R., Orlando, F., et al. (2016). Colistin enhances therapeutic efficacy of daptomycin or teicoplanin in a murine model of multiresistant Acinetobacter baumannii sepsis. Diagn. Microbiol. Infect. Dis. 86, 392-398. doi: 10.1016/j. diagmicrobio.2016.09.010

Cobo, E. R., and Chadee, K. (2013). Antimicrobial human $\beta$-defensins in the colon and their role in infectious and non-infectious diseases. Pathogens 2, 177-192. doi: 10.3390/pathogens2010177

Collinet-Adler, S., Castro, C. A., Ledonio, C. G. T., Bechtold, J. E., and Tsukayama, D. T. (2011). Acinetobacter baumannii is not associated with osteomyelitis in a rat model: a pilot study. Clin. Orthop. Relat. Res. 469, 274-282. doi: 10.1007/s11999-010-1488-0

Crane, D. P., Gromov, K., Li, D., Søballe, K., Wahnes, C., Büchner, H., et al. (2009). Efficacy of colistin-impregnated beads to prevent multidrug-resistant A. baumannii implant-associated osteomyelitis. J. Orthop. Res. 27, 1008-1015. doi: $10.1002 /$ jor.20847

Crépin, S., Ottosen, E. N., Peters, K., Smith, S. N., Himpsl, S. D., Vollmer, W., et al. (2018). The lytic transglycosylase MltB connects membrane homeostasis and in vivo fitness of Acinetobacter baumannii. Mol. Microbiol. 109, 745-762. doi: $10.1111 / \mathrm{mmi} .14000$

Dai, T., Tegos, G. P., Lu, Z., Huang, L., Zhiyentayev, T., Franklin, M. J., et al. (2009). Photodynamic therapy for Acinetobacter baumannii burn infections in mice. Antimicrob. Agents Chemother. 53, 3929-3934. doi: 10.1128/ AAC.00027-09

Dave, S., Brooks-Walter, A., Pangburn, M. K., and McDaniel, L. S. (2001). PspC, a pneumococcal surface protein, binds human factor H. Infect. Immun. 69, 3435-3437. doi: 10.1128/IAI.69.5.3435-3437.2001

De Breij, A., Eveillard, M., Dijkshoorn, L., Van Den Broek, P. J., Nibbering, P. H., and Joly-Guillou, M.-L. (2012). Differences in Acinetobacter baumannii strains and host innate immune response determine morbidity and mortality in experimental pneumonia. PLoS One 7:e30673. doi: 10.1371/journal. pone. 0030673

De Breij, A., Gaddy, J., Van Der Meer, J., Koning, R., Koster, A., Van Den Broek, P., et al. (2009). CsuA/BABCDE-dependent pili are not involved in the adherence of Acinetobacter baumannii ATCC19606T to human airway epithelial cells and their inflammatory response. Res. Microbiol. 160, 213-218. doi: 10.1016/j. resmic.2009.01.002

De Léséleuc, L., Harris, G., Kuolee, R., Xu, H. H., and Chen, W. (2014). Serum resistance, gallium nitrate tolerance and extrapulmonary dissemination are linked to heme consumption in a bacteremic strain of Acinetobacter baumannii. Int. J. Med. Microbiol. 304, 360-369. doi: 10.1016/j.ijmm.2013.12.002

De Silva, P. M., Chong, P., Fernando, D. M., Westmacott, G., and Kumar, A. (2017). Effect of incubation temperature on antibiotic resistance and virulence factors of Acinetobacter baumannii ATCC 17978. Antimicrob. Agents Chemother. 62, e01514-e01517. doi: 10.1128/AAC.01514-17

Deveson Lucas, D., Crane, B., Wright, A., Han, M.-L., Moffatt, J., Bulach, D., et al. (2018). Emergence of high-level colistin resistance in an Acinetobacter baumannii clinical isolate mediated by inactivation of the global regulator H-NS. Antimicrob. Agents Chemother. 62, e02442-17. doi: 10.1128/AAC.02442-17

Dexter, C., Murray, G. L., Paulsen, I. T., and Peleg, A. Y. (2015). Communityacquired Acinetobacter baumannii: clinical characteristics, epidemiology and pathogenesis. Expert Rev. Anti-Infect. Ther. 13, 567-573. doi: 10.1586/14787210.2015.1025055

Diancourt, L., Passet, V., Nemec, A., Dijkshoorn, L., and Brisse, S. (2010). The population structure of Acinetobacter baumannii: expanding multiresistant clones from an ancestral susceptible genetic Pool. PLoS One 5:e10034. doi: 10.1371/journal.pone.0010034

Dikshit, N., Kale, S. D., Khameneh, H. J., Balamuralidhar, V., Tang, C. Y., Kumar, P., et al. (2017). NLRP3 inflammasome pathway has a critical role in the host immunity against clinically relevant Acinetobacter baumannii pulmonary infection. Mucosal Immunol. 11, 257-272. doi: 10.1038/mi.2017.50
Du, D., Wang-Kan, X., Neuberger, A., Van Veen, H. W., Pos, K. M., Piddock, L. J. V., et al. (2018). Multidrug efflux pumps: structure, function and regulation. Nat. Rev. Microbiol. 16, 523-539. doi: 10.1038/s41579-018-0048-6

Eijkelkamp, B. A., Hassan, K. A., Paulsen, I. T., and Brown, M. H. (2011). Investigation of the human pathogen Acinetobacter baumannii under iron limiting conditions. BMC Genomics 12:126. doi: 10.1186/1471-2164-12-126

Eijkelkamp, B. A., Stroeher, U. H., Hassan, K. A., Elbourne, L. D. H., Paulsen, I. T., and Brown, M. H. (2013). H-NS plays a role in expression of Acinetobacter baumannii virulence features. Infect. Immun. 81, 2574-2583. doi: 10.1128/ IAI.00065-13

Eijkelkamp, B. A., Stroeher, U. H., Hassan, K. A., Paulsen, I. T., and Brown, M. H. (2014). Comparative analysis of surface-exposed virulence factors of Acinetobacter baumannii. BMC Genomics 15:1020. doi: 10.1186/1471-2164-15-1020

Elhosseiny, N. M., Amin, M. A., Yassin, A. S., and Attia, A. S. (2015). Acinetobacter baumannii universal stress protein A plays a pivotal role in stress response and is essential for pneumonia and sepsis pathogenesis. Int. J. Med. Microbiol. 305, 114-123. doi: 10.1016/j.ijmm.2014.11.008

Elhosseiny, N. M., and Attia, A. S. (2018). Acinetobacter: an emerging pathogen with a versatile secretome. Emerg. Microb. Infect. 7, 1-15. doi: 10.1038/ s41426-018-0030-4

Eliopoulos, G. M., Maragakis, L. L., and Perl, T. M. (2008). Acinetobacter baumannii: epidemiology, antimicrobial resistance, and treatment options. Clin. Infect. Dis. 46, 1254-1263. doi: 10.1086/529198

Ellett, F., Pase, L., Hayman, J. W., Andrianopoulos, A., and Lieschke, G. J. (2010). mpeg1 promoter transgenes direct macrophage-lineage expression in zebrafish. Blood 117, e49-e56. doi: 10.1182/blood-2010-10-314120

Esin, S., Batoni, G., Counoupas, C., Stringaro, A., Brancatisano, F. L., Colone, M., et al. (2008). Direct binding of human NK cell natural cytotoxicity receptor NKp44 to the surfaces of Mycobacteria and other bacteria. Infect. Immun. 76, 1719-1727. doi: 10.1128/IAI.00870-07

Eveillard, M., Soltner, C., Kempf, M., Saint-André, J.-P., Lemarié, C., Randrianarivelo, C., et al. (2010). The virulence variability of different Acinetobacter baumannii strains in experimental pneumonia. J. Inf. Secur. 60, 154-161. doi: 10.1016/j.jinf.2009.09.004

Falagas, M., Karveli, E., Kelesidis, I., and Kelesidis, T. (2007). Communityacquired Acinetobacter infections. Eur. J. Clin. Microbiol. Infect. Dis. 26, 857-868. doi: 10.1007/s10096-007-0365-6

Ferreira, V. P., Pangburn, M. K., and Cortés, C. (2010). Complement control protein factor $\mathrm{H}$ : the good, the bad, and the inadequate. Mol. Immunol. 47, 2187-2197. doi: 10.1016/j.molimm.2010.05.007

Fiester, S. E., Arivett, B. A., Schmidt, R. E., Beckett, A. C., Ticak, T., Carrier, M. V., et al. (2016). Iron-regulated phospholipase C activity contributes to the cytolytic activity and virulence of Acinetobacter baumannii. PLoS One 11:e0167068. doi: 10.1371/journal.pone.0167068

Fitzsimons, T. C., Lewis, J. M., Wright, A., Kleifeld, O., Schittenhelm, R. B., Powell, D., et al. (2018). Identification of novel Acinetobacter baumannii type VI secretion system anti-bacterial effector and immunity pairs. Infect. Immun. 86, e00297-18. doi: 10.1128/IAI.00297-18

Fleming, I. D., Krezalek, M. A., Belogortseva, N., Zaborin, A., Defazio, J., Chandrasekar, L., et al. (2017). Modeling Acinetobacter baumannii wound infections: the critical role of iron. J. Trauma Acute Care Surg. 82, 557-565. doi: 10.1097/TA.0000000000001338

Freire, M. P., De Oliveira Garcia, D., Garcia, C. P., Campagnari Bueno, M. F., Camargo, C. H., Kono Magri, A. S. G., et al. (2016). Bloodstream infection caused by extensively drug-resistant Acinetobacter baumannii in cancer patients: high mortality associated with delayed treatment rather than with the degree of neutropenia. Clin. Microbiol. Infect. 22, 352-358. doi: 10.1016/j. cmi.2015.12.010

Gaddy, J. A., Arivett, B. A., McConnell, M. J., López-Rojas, R., Pachón, J., and Actis, L. A. (2012). Role of Acinetobactin-mediated iron acquisition functions in the interaction of Acinetobacter baumannii strain ATCC $19606 \mathrm{~T}$ with human lung epithelial cells, Galleria mellonella caterpillars, and mice. Infect. Immun. 80, 1015-1024. doi: 10.1128/IAI.06279-11

Gallagher, L. A., Ramage, E., Weiss, E. J., Radey, M., Hayden, H. S., Held, K. G., et al. (2015). Resources for genetic and genomic analysis of emerging pathogen Acinetobacter baumannii. J. Bacteriol. 197, 2027-2035. doi: 10.1128/ JB.00131-15

Garcia, A., Solar, H., Gonzalez, C., and Zemelman, R. (2000). Effect of EDTA on the resistance of clinical isolates of Acinetobacter baumannii to the 
bactericidal activity of normal human serum. J. Med. Microbiol. 49, 1047-1050. doi: 10.1099/0022-1317-49-11-1047

García-Garmendia, J.-L., Ortiz-Leyba, C., Garnacho-Montero, J., Jiménez-Jiménez, F.-J., Pérez-Paredes, C., Barrero-Almodóvar, A. E., et al. (2001). Risk factors for Acinetobacter baumannii nosocomial bacteremia in critically ill patients: a cohort study. Clin. Infect. Dis. 33, 939-946. doi: 10.1086/322584

García-Patiño, M. G., García-Contreras, R., and Licona-Limón, P. (2017). The immune response against Acinetobacter baumannii, an emerging pathogen in nosocomial infections. Front. Immunol. 8:441. doi: 10.3389/fimmu. 2017.00441

García-Quintanilla, M., Pulido, M. R., Pachón, J., and McConnell, M. J. (2014). Immunization with lipopolysaccharide-deficient whole cells provides protective immunity in an experimental mouse model of Acinetobacter baumannii infection. PLoS One 9:e114410. doi: 10.1371/journal.pone.0114410

Garg, N., Singh, R., Shukla, G., Capalash, N., and Sharma, P. (2016). Immunoprotective potential of in silico predicted Acinetobacter baumannii outer membrane nuclease, NucAb. Int. J. Med. Microbiol. 306, 1-9. doi: 10.1016/j.ijmm.2015.10.005

Gebhardt, M. J., Gallagher, L. A., Jacobson, R. K., Usacheva, E. A., Peterson, L. R., Zurawski, D. V., et al. (2015). Joint transcriptional control of virulence and resistance to antibiotic and environmental stress in Acinetobacter baumannii. MBio 6, e01660-15. doi: 10.1128/mBio.01660-15

Geisinger, E., and Isberg, R. R. (2015). Antibiotic modulation of capsular exopolysaccharide and virulence in Acinetobacter baumannii. PLoS Pathog. 11:e1004691. doi: 10.1371/journal.ppat.1004691

Geisinger, E., Mortman, N. J., Vargas-Cuebas, G., Tai, A. K., and Isberg, R. R. (2018). A global regulatory system links virulence and antibiotic resistance to envelope homeostasis in Acinetobacter baumannii. PLoS Pathog. 14:e1007030. doi: 10.1371/journal.ppat.1007030

Geng, S., Matsushima, H., Okamoto, T., Yao, Y., Lu, R., Page, K., et al. (2013). Emergence, origin, and function of neutrophil-dendritic cell hybrids in experimentally induced inflammatory lesions in mice. Blood 121, 1690-1700. doi: 10.1182/blood-2012-07-445197

Goh, H. M. S., Beatson, S. A., Totsika, M., Moriel, D. G., Phan, M.-D., Szubert, J., et al. (2013). Molecular analysis of the Acinetobacter baumannii biofilmassociated protein. Appl. Environ. Microbiol. 79, 6535-6543. doi: 10.1128/ AEM.01402-13

Greenwald, G. I., and Ganz, T. (1987). Defensins mediate the microbicidal activity of human neutrophil granule extract against Acinetobacter calcoaceticus. Infect. Immun. 55, 1365-1368.

Hall, C., Flores, M. V., Storm, T., Crosier, K., and Crosier, P. (2007). The zebrafish lysozyme $\mathrm{C}$ promoter drives myeloid-specific expression in transgenic fish. BMC Dev. Biol. 7:42. doi: 10.1186/1471-213X-7-42

Hall-Stoodley, L., Costerton, J. W., and Stoodley, P. (2004). Bacterial biofilms: from the natural environment to infectious diseases. Nat. Rev. Microbiol. 2, 95-108. doi: 10.1038/nrmicro821

Harding, C. M., Hennon, S. W., and Feldman, M. F. (2017a). Uncovering the mechanisms of Acinetobacter baumannii virulence. Nat. Rev. Microbiol. 16, 91-102. doi: 10.1038/nrmicro.2017.148

Harding, C. M., Kinsella, R. L., Palmer, L. D., Skaar, E. P., and Feldman, M. F. (2016). Medically relevant Acinetobacter species require a type II secretion system and specific membrane-associated chaperones for the export of multiple substrates and full virulence. PLoS Pathog. 12:e1005391. doi: 10.1371/ journal.ppat.1005391

Harding, C. M., Pulido, M. R., Di Venanzio, G., Kinsella, R. L., Webb, A. I., Scott, N. E., et al. (2017b). Pathogenic Acinetobacter species have a functional type I secretion system and contact-dependent inhibition systems. J. Biol. Chem. 292, 9075-9087. doi: 10.1074/jbc.M117.781575

Hassan, K. A., Jackson, S. M., Penesyan, A., Patching, S. G., Tetu, S. G., Eijkelkamp, B. A., et al. (2013). Transcriptomic and biochemical analyses identify a family of chlorhexidine efflux proteins. Proc. Natl. Acad. Sci. 110, 20254-20259. doi: 10.1073/pnas.1317052110

Hasselbring, B. M., Patel, M. K., and Schell, M. A. (2011). Dictyostelium discoideum as a model system for identification of Burkholderia pseudomallei virulence factors. Infect. Immun. 79, 2079-2088. doi: 10.1128/IAI.01233-10

Hee, C. C., Hee, H. S., Young, L. J., Sik, L. J., Seok, L. Y., Ae, K. S., et al. (2008). Acinetobacter baumannii outer membrane protein A targets the nucleus and induces cytotoxicity. Cell. Microbiol. 10, 309-319. doi: 10.1111/j. 1462-5822.2007.01041.x
Hee, C. C., Young, L. E., Chul, L. Y., In, P. T., Jung, K. H., Hee, H. S., et al. (2005). Outer membrane protein 38 of Acinetobacter baumannii localizes to the mitochondria and induces apoptosis of epithelial cells. Cell. Microbiol. 7, 1127-1138. doi: 10.1111/j.1462-5822.2005.00538.x

Henderson, I. R., Cappello, R., and Nataro, J. P. (2000). Autotransporter proteins, evolution and redefining protein secretion. Trends Microbiol. 8, 529-532. doi: $10.1016 /$ S0966-842X(00)01853-9

Henderson, I. R., Navarro-Garcia, F., Desvaux, M., Fernandez, R. C., and Alảaldeen, D. (2004). Type V protein secretion pathway: the autotransporter story. Microbiol. Mol. Biol. Rev. 68, 692-744. doi: 10.1128/MMBR.68.4.692-744.2004

Hood, M. I., and Skaar, E. P. (2012). Nutritional immunity: transition metals at the pathogen-host interface. Nat. Rev. Microbiol. 10, 525-537. doi: 10.1038/ nrmicro2836

Hornsey, M., Phee, L., Longshaw, C., and Wareham, D. W. (2013). In vivo efficacy of telavancin/colistin combination therapy in a Galleria mellonella model of Acinetobacter baumannii infection. Int. J. Antimicrob. Agents 41, 285-287. doi: 10.1016/j.ijantimicag.2012.11.013

Hornsey, M., and Wareham, D. W. (2011). In vivo efficacy of glycopeptide/ colistin combination therapies in a Galleria mellonella model of Acinetobacter baumannii infection. Antimicrob. Agents Chemother. 55, 3534-3537. doi: 10.1128/AAC.00230-11

Hu, D., Liu, B., Dijkshoorn, L., Wang, L., and Reeves, P. R. (2013). Diversity in the major polysaccharide antigen of Acinetobacter baumannii assessed by DNA sequencing, and development of a molecular serotyping scheme. PLoS One 8:e70329. doi: 10.1371/journal.pone.0083821

Huang, W., Wang, S., Yao, Y., Xia, Y., Yang, X., Long, Q., et al. (2015). OmpW is a potential target for eliciting protective immunity agains Acinetobacter baumannii infections. Vaccine 33, 4479-4485. doi: 10.1016/j. vaccine.2015.07.031

Iacono, M., Villa, L., Fortini, D., Bordoni, R., Imperi, F., Bonnal, R. J. P., et al. (2008). Whole-genome pyrosequencing of an epidemic multidrug-resistant Acinetobacter baumannii strain belonging to the European clone II group. Antimicrob. Agents Chemother. 52, 2616-2625. doi: 10.1128/AAC.01643-07

Ishikawa, M., Yoshimoto, S., Hayashi, A., Kanie, J., and Hori, K. (2016). Discovery of a novel periplasmic protein that forms a complex with a trimeric autotransporter adhesin and peptidoglycan. Mol. Microbiol. 101, 394-410. doi: $10.1111 / \mathrm{mmi} .13398$

Islam, A. H. M. S., Singh, K.-K. B., and Ismail, A. (2011). Demonstration of an outer membrane protein that is antigenically specific for Acinetobacter baumannii. Diagn. Microbiol. Infect. Dis. 69, 38-44. doi: 10.1016/j. diagmicrobio.2010.09.008

Iwashkiw, J. A., Seper, A., Weber, B. S., Scott, N. E., Vinogradov, E., Stratilo, C., et al. (2012). Identification of a general O-linked protein glycosylation system in Acinetobacter baumannii and its role in virulence and biofilm formation. PLoS Pathog. 8:e1002758. doi: 10.1371/journal.ppat.1002758

Iyer, R., Moussa, S. H., Durand-Réville, T. F., Tommasi, R., and Miller, A. (2018). Acinetobacter baumannii OmpA is a selective antibiotic permeant porin. ACS Infect. Dis. 4, 373-381. doi: 10.1021/acsinfecdis.7b00168

Jacob-Dubuisson, F., Locht, C., and Antoine, R. (2001). Two-partner secretion in gram-negative bacteria: a thrifty, specific pathway for large virulence proteins. Mol. Microbiol. 40, 306-313. doi: 10.1046/j.1365-2958.2001.02278.x Jacob-Dubuisson, F., Villeret, V., Clantin, B., Delattre, A. S., and Saint, N. (2009). First structural insights into the TpsB/Omp85 superfamily. Biol. Chem. 390, 675-684. doi: 10.1515/BC.2009.099

Jacobs, A. C., Hood, I., Boyd, K. L., Olson, P. D., Morrison, J. M., Carson, S., et al. (2010). Inactivation of phospholipase D diminishes Acinetobacter baumannii pathogenesis. Infect. Immun. 78, 1952-1962. doi: 10.1128/ IAI.00889-09

Jahangiri, A., Rasooli, I., Owlia, P., Imani Fooladi, A. A., and Salimian, J. (2018). Highly conserved exposed immunogenic peptides of Omp34 against Acinetobacter baumannii: an innovative approach. J. Microbiol. Methods 144, 79-85. doi: 10.1016/j.mimet.2017.11.008

Jayamani, E., Rajamuthiah, R., Larkins-Ford, J., Fuchs, B. B., Conery, A. L., Vilcinskas, A., et al. (2015). Insect-derived cecropins display activity against Acinetobacter baumannii in a whole-animal high-throughput Caenorhabditis elegans model. Antimicrob. Agents Chemother. 59, 1728-1737. doi: 10.1128/ AAC.04198-14

Jin, J. S., Kwon, S.-O., Moon, D. C., Gurung, M., Lee, J. H., Kim, S. I., et al. (2011). Acinetobacter baumannii secretes cytotoxic outer membrane protein 
A via outer membrane vesicles. PLoS One 6:e17027. doi: 10.1371/journal. pone.0017027

Johnson, T. L., Waack, U., Smith, S., Mobley, H., and Sandkvist, M. (2016). Acinetobacter baumannii is dependent on the type II secretion system and its substrate LipA for lipid utilization and in vivo fitness. J. Bacteriol. 198, 711-719. doi: 10.1128/JB.00622-15

Joly-Guillou, M. L., Wolff, M., Pocidalo, J. J., Walker, F., and Carbon, C. (1997). Use of a new mouse model of Acinetobacter baumannii pneumonia to evaluate the postantibiotic effect of imipenem. Antimicrob. Agents Chemother. 41, 345-351. doi: 10.1128/AAC.41.2.345

Joseph, P. M., and Stephen, T. M. (2018). Expanding the paradigm for the outer membrane: Acinetobacter baumannii in the absence of endotoxin. Mol. Microbiol. 107, 47-56. doi: 10.1111/mmi.13872

Jousselin, A., Metzinger, L., and Felden, B. (2009). On the facultative requirement of the bacterial RNA chaperone, Hfq. Trends Microbiol. 17, 399-405. doi: 10.1016/j.tim.2009.06.003

Juttukonda, L. J., Chazin, W. J., and Skaar, E. P. (2016). Acinetobacter baumannii coordinates urea metabolism with metal import to resist host-mediated metal limitation. MBio 7, e01475-16. doi: 10.1128/mBio.01475-16

Kamoshida, G., Kikuchi-Ueda, T., Nishida, S., Tansho-Nagakawa, S., Ubagai, T., and Ono, Y. (2018). Pathogenic bacterium Acinetobacter baumannii inhibits the formation of neutrophil extracellular traps by suppressing neutrophil adhesion. Front. Immunol. 9:178. doi: 10.3389/fimmu.2018.00178

Kamoshida, G., Kikuchi-Ueda, T., Tansho-Nagakawa, S., Nakano, R., Nakano, A., Kikuchi, H., et al. (2015). Acinetobacter baumannii escape from neutrophil extracellular traps (NETs). J. Infect. Chemother. 21, 43-49. doi: 10.1016/j. jiac.2014.08.032

Kamoshida, G., Tansho-Nagakawa, S., Kikuchi-Ueda, T., Nakano, R., Hikosaka, K., Nishida, S., et al. (2016). A novel bacterial transport mechanism of Acinetobacter baumannii via activated human neutrophils through interleukin-8. J. Leukoc. Biol. 100, 1405-1412. doi: 10.1189/jlb.4AB0116-023RR

Kaparakis-Liaskos, M., and Ferrero, R. L. (2015). Immune modulation by bacterial outer membrane vesicles. Nat. Rev. Immunol. 15, 375-387. doi: $10.1038 /$ nri3837

Karageorgopoulos, D. E., and Falagas, M. E. (2008). Current control and treatment of multidrug-resistant Acinetobacter baumannii infections. Lancet Infect. Dis. 8, 751-762. doi: 10.1016/S1473-3099(08)70279-2

Kato, S., Kowashi, Y., and Demuth, D. R. (2002). Outer membrane-like vesicles secreted by Actinobacillus actinomycetemcomitans are enriched in leukotoxin. Microb. Pathog. 32, 1-13. doi: 10.1006/mpat.2001.0474

Kenyon, J. J., and Hall, R. M. (2013). Variation in the complex carbohydrate biosynthesis loci of Acinetobacter baumannii genomes. PLoS One 8:e62160. doi: 10.1371/journal.pone.0062160

Kikuchi-Ueda, T., Kamoshida, G., Ubagai, T., Nakano, R., Nakano, A., Akuta, T., et al. (2017). The TNF- $\alpha$ of mast cells induces pro-inflammatory responses during infection with Acinetobacter baumannii. Immunobiology 222, 1025-1034. doi: 10.1016/j.imbio.2017.05.015

Kim, S. W., Choi, C. H., Moon, D. C., Jin, J. S., Lee, J. H., Shin, J.-H., et al. (2009). Serum resistance of Acinetobacter baumannii through the binding of factor $\mathrm{H}$ to outer membrane proteins. FEMS Microbiol. Lett. 301, 224-231. doi: 10.1111/j.1574-6968.2009.01820.x

Kim, C., Kim, D., Lee, S., Jeong, Y., Kang, M., Lee, J., et al. (2014). Toll-like receptor 2 promotes bacterial clearance during the initial stage of pulmonary infection with Acinetobacter baumannii. Mol. Med. Rep. 9, 1410-1414. doi: 10.3892/mmr.2014.1966

King, L. B., Pangburn, M. K., and McDaniel, L. S. (2013). Serine protease PKF of Acinetobacter baumannii results in serum resistance and suppression of biofilm formation. J. Infect. Dis. 207, 1128-1134. doi: 10.1093/infdis/jis939

King, L. B., Swiatlo, E., Swiatlo, A., and McDaniel, L. S. (2009). Serum resistance and biofilm formation in clinical isolates of Acinetobacter baumannii. FEMS Immunol. Med. Microbiol. 55, 414-421. doi: 10.1111/j.1574-695X.2009.00538.x

Knapp, S., Wieland, C. W., Florquin, S., Pantophlet, R., Dijkshoorn, L., Tshimbalanga, N., et al. (2006). Differential roles of CD14 and toll-like receptors 4 and 2 in murine Acinetobacter pneumonia. Am. J. Respir. Crit. Care Med. 173, 122-129. doi: 10.1164/rccm.200505-730OC

Ko, W.-C., Lee, H.-C., Chiang, S.-R., Yan, J.-J., Wu, J.-J., Lu, C.-L., et al. (2004). In vitro and in vivo activity of meropenem and sulbactam against a multidrugresistant Acinetobacter baumannii strain. J. Antimicrob. Chemother. 53, 393-395. doi: 10.1093/jac/dkh080
Koenigs, A., Stahl, J., Averhoff, B., Göttig, S., Wichelhaus, T. A., Wallich, R., et al. (2016). CipA of Acinetobacter baumannii is a novel plasminogen binding and complement inhibitory protein. J. Infect. Dis. 213, 1388-1399. doi: 10.1093/infdis/jiv601

Koeppen, K., Hampton, T. H., Jarek, M., Scharfe, M., Gerber, S. A., Mielcarz, D. W., et al. (2016). A novel mechanism of host-pathogen interaction through sRNA in bacterial outer membrane vesicles. PLoS Pathog. 12:e1005672. doi: 10.1371/journal.ppat.1005672

Koiwai, K., Hartmann, M. D., Linke, D., Lupas, A. N., and Hori, K. (2016) Structural basis for toughness and flexibility in the C-terminal passenger domain of an Acinetobacter trimeric autotransporter adhesin. J. Biol. Chem. 291, 3705-3724. doi: 10.1074/jbc.M115.701698

Konstantinidis, T., Kambas, K., Mitsios, A., Panopoulou, M., Tsironidou, V., Dellaporta, E., et al. (2016). Immunomodulatory role of clarithromycin in Acinetobacter baumannii infection via formation of neutrophil extracellular traps. Antimicrob. Agents Chemother. 60, 1040-1048. doi: 10.1128/AAC.02063-15

Kuehn, M. J., and Kesty, N. C. (2005). Bacterial outer membrane vesicles and the host-pathogen interaction. Genes Dev. 19, 2645-2655. doi: 10.1101/gad.1299905

Kulesus, R. R., Diaz-Perez, K., Slechta, E. S., Eto, D. S., and Mulvey, M. A. (2008). Impact of the RNA chaperone $\mathrm{Hfq}$ on the fitness and virulence potential of uropathogenic Escherichia coli. Infect. Immun. 76, 3019-3026. doi: 10.1128/IAI.00022-08

Kulkarni, H. M., and Jagannadham, M. V. (2014). Biogenesis and multifaceted roles of outer membrane vesicles from gram-negative bacteria. Microbiology 160, 2109-2121. doi: 10.1099/mic.0.079400-0

Kuo, H.-Y., Chao, H.-H., Liao, P.-C., Hsu, L., Chang, K.-C., Tung, C.-H., et al. (2017). Functional characterization of Acinetobacter baumannii lacking the RNA chaperone Hfq. Front. Microbiol. 8:2068. doi: 10.3389/fmicb.2017.02068

Kuolee, R., Harris, G., Yan, H., Xu, H. H., Conlan, W. J., Patel, G. B., et al. (2015). Intranasal immunization protects against Acinetobacter baumanniiassociated pneumonia in mice. Vaccine 33, 260-267. doi: 10.1016/j. vaccine.2014.02.083

Kwon, S.-O., Gho, Y. S., Lee, J. C., and Kim, S. I. (2009). Proteome analysis of outer membrane vesicles from a clinical Acinetobacter baumannii isolate. FEMS Microbiol. Lett. 297, 150-156. doi: 10.1111/j.1574-6968.2009.01669.x

Laarman, A. J., Ruyken, M., Malone, C. L., Van Strijp, J. A. G., Horswill, A. R. and Rooijakkers, S. H. M. (2011). Staphylococcus aureus metalloprotease aureolysin cleaves complement C3 to mediate immune evasion. J. Immunol. 186, 6445-6453. doi: 10.4049/jimmunol.1002948

Lázaro-Díez, M., Chapartegui-González, I., Redondo-Salvo, S., Leigh, C., Merino, D., Segundo, D. S., et al. (2017). Human neutrophils phagocytose and kill Acinetobacter baumannii and A. pittii. Sci. Rep. 7:4571. doi: 10.1038/ s41598-017-04870-8

Lázaro-Díez, M., Navascués-Lejarza, T., Remuzgo-Martínez, S., Navas, J., Icardo, J. M., Acosta, F., et al. (2016). Acinetobacter baumannii and A. pittii clinical isolates lack adherence and cytotoxicity to lung epithelial cells in vitro. Microbes Infect. 18, 559-564. doi: 10.1016/j.micinf.2016.05.002

Lee, J. S., Choi, C. H., Kim, J. W., and Lee, J. C. (2010). Acinetobacter baumannii outer membrane protein a induces dendritic cell death through mitochondrial targeting. J. Microbiol. 48, 387-392. doi: 10.1007/s12275-010-0155-1

Lee, J. S., Lee, J. C., Lee, C.-M., Jung, I. D., Jeong, Y.-I., Seong, E.-Y., et al. (2007). Outer membrane protein A of Acinetobacter baumannii induces differentiation of CD4+ T cells toward a Th1 polarizing phenotype through the activation of dendritic cells. Biochem. Pharmacol. 74, 86-97. doi: 10.1016/j. bcp.2007.02.012

Lees-Miller, R. G., Iwashkiw, J. A., Scott, N. E., Seper, A., Vinogradov, E., Schild, S., et al. (2013). A common pathway for O-linked protein-glycosylation and synthesis of capsule in Acinetobacter baumannii. Mol. Microbiol. 89, 816-830. doi: $10.1111 / \mathrm{mmi} .12300$

Leo, J. C., Grin, I., and Linke, D. (2012). Type V secretion: mechanism(s) of autotransport through the bacterial outer membrane. Philos. Trans. R. Soc Bio. Sci. 367, 1088-1101. doi: 10.1098/rstb.2011.0208

Li, L., Jin, H., Xu, J., Shi, Y., and Wen, Z. (2010). Irf8 regulates macrophage versus neutrophil fate during zebrafish primitive myelopoiesis. Blood 117, 1359-1369. doi: 10.1182/blood-2010-06-290700

Lin, M.-F., Lin, Y.-Y., Yeh, H.-W., and Lan, C.-Y. (2014). Role of the BaeSR two-component system in the regulation of Acinetobacter baumannii adeAB genes and its correlation with tigecycline susceptibility. BMC Microbiol. 14:119. doi: 10.1186/1471-2180-14-119 
Lin, L., Tan, B., Pantapalangkoor, P., Ho, T., Baquir, B., Tomaras, A., et al. (2012). Inhibition of LpxC protects mice from resistant Acinetobacter baumannii by modulating inflammation and enhancing phagocytosis. MBio 3, e00312-12. doi: $10.1128 / \mathrm{mBio} .00312-12$

Liou, M.-L., Soo, P.-C., Ling, S.-R., Kuo, H.-Y., Tang, C. Y., and Chang, K.-C. (2014). The sensor kinase BfmS mediates virulence in Acinetobacter baumannii. J. Microbiol. Immunol. Infect. 47, 275-281. doi: 10.1016/j.jmii.2012.12.004

Liu, Q., Hassan, K. A., Ashwood, H. E., Gamage, H. K. A. H., Li, L., Mabbutt, B. C., et al. (2018). Regulation of the aceI multidrug efflux pump gene in Acinetobacter baumannii. J. Antimicrob. Chemother. 73, 1492-1500. doi: 10.1093/jac/dky034

Liu, C.-C., Kuo, H.-Y., Tang, C. Y., Chang, K.-C., and Liou, M.-L. (2014). Prevalence and mapping of a plasmid encoding a type IV secretion system in Acinetobacter baumannii. Genomics 104, 215-223. doi: 10.1016/j. ygeno.2014.07.011

Liu, D., Liu, Z.-S., Hu, P., Cai, L., Fu, B.-Q., Li, Y.-S., et al. (2016). Characterization of surface antigen protein 1 (SurA1) from Acinetobacter baumannii and its role in virulence and fitness. Vet. Microbiol. 186, 126-138. doi: 10.1016/j. vetmic.2016.02.018

Loehfelm, T. W., Luke, N. R., and Campagnari, A. A. (2008). Identification and characterization of an Acinetobacter baumannii biofilm-associated protein. J. Bacteriol. 190, 1036-1044. doi: 10.1128/JB.01416-07

Lood, R., Winer, B. Y., Pelzek, A. J., Diez-Martinez, R., Thandar, M., Euler, C. W., et al. (2015). Novel phage lysins capable of killing the multidrug resistant gram-negative bacterium Acinetobacter baumannii in a mouse sepsis model. Antimicrob. Agents Chemother. 59, 1983-1991. doi: 10.1128/AAC.04641-14

Lopalco, P., Stahl, J., Annese, C., Averhoff, B., and Corcelli, A. (2017). Identification of unique cardiolipin and monolysocardiolipin species in Acinetobacter baumannii. Sci. Rep. 7:2972. doi: 10.1038/s41598-017-03214-w

Luo, G., Lin, L., Ibrahim, A. S., Baquir, B., Pantapalangkoor, P., Bonomo, R. A., et al. (2012). Active and passive immunization protects against lethal, extreme drug resistant-Acinetobacter baumannii infection. PLoS One 7:e29446. doi: 10.1371/journal.pone.0051008

Manning, A. J., and Kuehn, M. J. (2011). Contribution of bacterial outer membrane vesicles to innate bacterial defense. BMC Microbiol. 11, 258-258. doi: 10.1186/1471-2180-11-258

Manuella, C.-F., Sara, M., Laurent, G., Luis, J., Gaël, C., Virginie, M., et al. (2016). The outer membrane porin OmpW of Acinetobacter baumannii is involved in iron uptake and colistin binding. FEBS Lett. 590, 224-231. doi: 10.1002/1873-3468.12050

March, C., Regueiro, V., Llobet, E., Moranta, D., Morey, P., Garmendia, J., et al. (2010). Dissection of host cell signal transduction during Acinetobacter baumannii - triggered inflammatory response. PLoS One 5:e10033. doi: 10.1371/journal.pone.0010033

Marchand, I., Damier-Piolle, L., Courvalin, P., and Lambert, T. (2004). Expression of the RND-type efflux pump AdeABC in Acinetobacter baumannii is regulated by the AdeRS two-component system. Antimicrob. Agents Chemother. 48, 3298-3304. doi: 10.1128/AAC.48.9.3298-3304.2004

Marti, S., Nait Chabane, Y., Alexandre, S., Coquet, L., Vila, J., Jouenne, T., et al. (2011). Growth of Acinetobacter baumannii in pellicle enhanced the expression of potential virulence factors. PLoS One 6:e26030. doi: 10.1371/ journal.pone.0026030

Martín-Aspas, A., Guerrero-Sánchez, F. M., García-Colchero, F., Rodríguez-Roca, S., and Girón-González, J.-A. (2018). Differential characteristics of Acinetobacter baumannii colonization and infection: risk factors, clinical picture, and mortality. Inf. Drug Resist. 11, 861-872. doi: 10.2147/IDR.S163944

Matsushima, H., Geng, S., Lu, R., Okamoto, T., Yao, Y., Mayuzumi, N., et al. (2013). Neutrophil differentiation into a unique hybrid population exhibiting dual phenotype and functionality of neutrophils and dendritic cells. Blood 121, 1677-1689. doi: 10.1182/blood-2012-07-445189

McBroom, A. J., and Kuehn, M. J. (2005). Outer membrane vesicles. EcoSal Plus 1. doi: 10.1128/ecosal.2.2.4

McBroom, A. J., and Kuehn, M. J. (2007). Release of outer membrane vesicles by gram-negative bacteria is a novel envelope stress response. Mol. Microbiol. 63, 545-558. doi: 10.1111/j.1365-2958.2006.05522.x

McConnell, M. J., Actis, L., and Pachón, J. (2013). Acinetobacter baumannii: human infections, factors contributing to pathogenesis and animal models. FEMS Microbiol. Rev. 37, 130-155. doi: 10.1111/j.1574-6976.2012.00344.x

McConnell, M. J., Domínguez-Herrera, J., Smani, Y., López-Rojas, R., Docobo-Pérez, F., and Pachón, J. (2011a). Vaccination with outer membrane complexes elicits rapid protective immunity to multidrug-resistant Acinetobacter baumannii. Infect. Immun. 79, 518-526. doi: 10.1128/IAI.00741-10

McConnell, M. J., and Pachón, J. (2010). Active and passive immunization against Acinetobacter baumannii using an inactivated whole cell vaccine. Vaccine 29, 1-5. doi: 10.1016/j.vaccine.2010.10.052

McConnell, M. J., Rumbo, C., Bou, G., and Pachón, J. (2011b). Outer membrane vesicles as an acellular vaccine against Acinetobacter baumannii. Vaccine 29, 5705-5710. doi: 10.1016/j.vaccine.2011.06.001

McMahon, K. J., Castelli, M. E., Vescovi, E. G., and Feldman, M. F. (2012). Biogenesis of outer membrane vesicles in Serratia marcescens is thermoregulated and can be induced by activation of the Rcs phosphorelay system. J. Bacteriol. 194, 3241-3249. doi: 10.1128/JB.00016-12

Meumann, E. M., Anstey, N. M., Currie, B. J., Piera, K. A., Kenyon, J. J., Hall, R. M., et al. (2019). Genomic epidemiology of severe community-onset Acinetobacter baumannii infection. Microb. Genom. 5:e000258. doi: 10.1099/ mgen.0.000258.

Moffatt, J. H., Harper, M., Harrison, P., Hale, J. D. F., Vinogradov, E., Seemann, T., et al. (2010). Colistin resistance in Acinetobacter baumannii is mediated by complete loss of lipopolysaccharide production. Antimicrob. Agents Chemother. 54, 4971-4977. doi: 10.1128/AAC.00834-10

Moffatt, J. H., Harper, M., Mansell, A., Crane, B., Fitzsimons, T. C., Nation, R. L., et al. (2013). Lipopolysaccharide-deficient Acinetobacter baumannii shows altered signaling through host toll-like receptors and increased susceptibility to the host antimicrobial peptide LL-37. Infect. Immun. 81, 684-689. doi: 10.1128/IAI.01362-12

Mohamed, M. F., Brezden, A., Mohammad, H., Chmielewski, J., and Seleem, M. N. (2017). A short D-enantiomeric antimicrobial peptide with potent immunomodulatory and antibiofilm activity against multidrug-resistant Pseudomonas aeruginosa and Acinetobacter baumannii. Sci. Rep. 7:6953. doi: 10.1038/s41598-017-07440-0

Moon, D. C., Choi, C. H., Lee, J. H., Choi, C.-W., Kim, H.-Y., Park, J. S., et al. (2012). Acinetobacter baumannii outer membrane protein a modulates the biogenesis of outer membrane vesicles. J. Microbiol. 50, 155-160. doi: 10.1007/s12275-012-1589-4

Moon, K. H., Weber, B. S., and Feldman, M. F. (2017). Subinhibitory concentrations of trimethoprim and sulfamethoxazole prevent biofilm formation by Acinetobacter baumannii through inhibition of Csu Pilus expression. Antimicrob. Agents Chemother. 61, e00778-17. doi: 10.1128/AAC.00778-17

Mortensen, B. L., Rathi, S., Chazin, W. J., and Skaar, E. P. (2014). Acinetobacter baumannii response to host-mediated zinc limitation requires the transcriptional regulator Zur. J. Bacteriol. 196, 2616-2626. doi: 10.1128/JB.01650-14

Mostowy, S., Boucontet, L., Mazon Moya, M. J., Sirianni, A., Boudinot, P., Hollinshead, M., et al. (2013). The Zebrafish as a new model for the in vivo study of Shigella flexneri interaction with phagocytes and bacterial autophagy. PLoS Pathog. 9:e1003588. doi: 10.1371/journal.ppat.1003588

Murray, G. L., Tsyganov, K., Kostoulias, X. P., Bulach, D. M., Powell, D., Creek, D. J., et al. (2017). Global gene expression profile of Acinetobacter baumannii during bacteremia. J. Infect. Dis. 215, S52-S57. doi: 10.1093/infdis/jiw529

Nairn, B. L., Lonergan, Z. R., Wang, J., Braymer, J. J., Zhang, Y., Calcutt, M. W., et al. (2016). The response of Acinetobacter baumannii to zinc starvation. Cell Host Microbe 19, 826-836. doi: 10.1016/j.chom.2016.05.007

Niu, C., Clemmer, K. M., Bonomo, R. A., and Rather, P. N. (2008). Isolation and characterization of an autoinducer synthase from Acinetobacter baumannii. J. Bacteriol. 190, 3386-3392. doi: 10.1128/JB.01929-07

Nordenfelt, P., and Tapper, H. (2011). Phagosome dynamics during phagocytosis by neutrophils. J. Leukoc. Biol. 90, 271-284. doi: 10.1189/jlb.0810457

Noto, M. J., Boyd, K. L., Burns, W. J., Varga, M. G., Peek, R. M., and Skaar, E. P. (2015). Toll-like receptor 9 contributes to defense against Acinetobacter baumannii infection. Infect. Immun. 83, 4134-4141. doi: 10.1128/IAI.00410-15

O’Hara, J. A., Ambe, L. A., Casella, L. G., Townsend, B. M., Pelletier, M. R., Ernst, R. K., et al. (2013). Activity of Vancomycin-containing regimens against colistin-resistant Acinetobacter baumannii clinical strains. Antimicrob. Agents Chemother. 57, 2103-2108. doi: 10.1128/AAC.02501-12

Obana, Y., Nishino, T., and Tanino, T. (1985). In-vitro and in-vivo activities of antimicrobial agents against Acinetobacter calcoaceticus. J. Antimicrob. Chemother. 15, 441-448. doi: 10.1093/jac/15.4.441

Pachón-Ibáñez, M. E., Docobo-Pérez, F., López-Rojas, R., Domínguez-Herrera, J., Jiménez-Mejias, M. E., García-Curiel, A., et al. (2010). Efficacy of Rifampin and its combinations with imipenem, 
sulbactam, and colistin in experimental models of infection caused by imipenem-resistant Acinetobacter baumannii. Antimicrob. Agents Chemother. 54, 1165-1172. doi: 10.1128/AAC.00367-09

Paidipally, P., Tripathi, D., Van, A., Radhakrishnan, R. K., Dhiman, R., Venkatasubramanian, S., et al. (2018). Interleukin-21 regulates natural killer cell responses during Mycobacterium tuberculosis infection. J. Infect. Dis. 217, 1323-1333. doi: 10.1093/infdis/jiy034

Park, J. S., Lee, W. C., Yeo, K. J., Ryu, K.-S., Kumarasiri, M., Hesek, D., et al. (2012). Mechanism of anchoring of OmpA protein to the cell wall peptidoglycan of the gram-negative bacterial outer membrane. FASEB J. 26, 219-228. doi: 10.1096/f.11-188425

Patamatamkul, S., Klungboonkrong, V., Praisarnti, P., and Jirakiat, K. (2017). A case-control study of community-acquired Acinetobacter baumannii pneumonia and melioidosis pneumonia in Northeast Thailand: an emerging fatal disease with unique clinical features. Diagn. Microbiol. Infect. Dis. 87, 79-86. doi: 10.1016/j.diagmicrobio.2016.10.014

Peleg, A. Y., Jara, S., Monga, D., Eliopoulos, G. M., Moellering, R. C., and Mylonakis, E. (2009). Galleria mellonella as a model system to study Acinetobacter baumannii pathogenesis and therapeutics. Antimicrob. Agents Chemother. 53, 2605-2609. doi: 10.1128/AAC.01533-08

Peleg, A. Y., Seifert, H., and Paterson, D. L. (2008a). Acinetobacter baumannii: emergence of a successful pathogen. Clin. Microbiol. Rev. 21, 538-582. doi: 10.1128/CMR.00058-07

Peleg, A. Y., Tampakakis, E., Fuchs, B. B., Eliopoulos, G. M., Moellering, R. C., and Mylonakis, E. (2008b). Prokaryote-eukaryote interactions identified by using Caenorhabditis elegans. Proc. Natl. Acad. Sci. 105, 14585-14590. doi: 10.1073/pnas.0805048105

Peng, C., Han, J., Ye, X., and Zhang, X. (2018). IL-33 treatment attenuates the systemic inflammation reaction in Acinetobacter baumannii pneumonia by suppressing TLR4/NF-KB signaling. Inflammation 41, 870-877. doi: 10.1007/ s10753-018-0741-7

Peng, S.-Y., You, R.-I., Lai, M.-J., Lin, N.-T., Chen, L.-K., and Chang, K.-C. (2017). Highly potent antimicrobial modified peptides derived from the Acinetobacter baumannii phage endolysin LysAB2. Sci. Rep. 7:11477. doi: 10.1038/s41598-017-11832-7

Pérez, A., Merino, M., Rumbo-Feal, S., Álvarez-Fraga, L., Vallejo, J. A., Beceiro, A., et al. (2017). The FhaB/FhaC two-partner secretion system is involved in adhesion of Acinetobacter baumannii AbH12O-A2 strain. Virulence 8, 959-974. doi: 10.1080/21505594.2016.1262313

Prajsnar, T. K., Cunliffe, V. T., Foster, S. J., and Renshaw, S. A. (2008). A novel vertebrate model of Staphylococcus aureus infection reveals phagocytedependent resistance of zebrafish to non-host specialized pathogens. Cell. Microbiol. 10, 2312-2325. doi: 10.1111/j.1462-5822.2008.01213.x

Pulido, M. R., García-Quintanilla, M., Pachón, J., and McConnell, M. J. (2018). Immunization with lipopolysaccharide-free outer membrane complexes protects against Acinetobacter baumannii infection. Vaccine 36, 4153-4156. doi: 10.1016/j.vaccine.2018.05.113

Qiu, H., Kuolee, R., Harris, G., and Chen, W. (2009). Role of NADPH phagocyte oxidase in host defense against acute respiratory Acinetobacter baumannii infection in mice. Infect. Immun. 77, 1015-1021. doi: 10.1128/ IAI.01029-08

Qiu, H., Kuolee, R., Harris, G., Van Rooijen, N., Patel, G. B., and Chen, W. (2012). Role of macrophages in early host resistance to respiratory Acinetobacter baumannii infection. PLoS One 7:e40019. doi: 10.1371/journal. pone.0040019

Qiu, H., Li, Z., Kuolee, R., Harris, G., Gao, X., Yan, H., et al. (2016). Host resistance to intranasal Acinetobacter baumannii reinfection in mice. Pathog. Dis. 74, ftw048-ftw048. doi: 10.1093/femspd/ftw048

Renckens, R., Roelofs, J. J. T. H., Knapp, S., De Vos, A. F., Florquin, S., and Van Der Poll, T. (2006). The acute-phase response and serum amyloid A inhibit the inflammatory response to Acinetobacter baumannii pneumonia. J. Infect. Dis. 193, 187-195. doi: 10.1086/498876

Repizo, G. D. (2017). Prevalence of Acinetobacter baumannii strains expressing the type 6 secretion system in patients with bacteremia. Virulence 8, 1099-1101. doi: 10.1080/21505594.2017.1346768

Robenshtok, E., Paul, M., Leibovici, L., Fraser, A., Pitlik, S., Ostfeld, I., et al. (2006). The significance of Acinetobacter baumannii bacteraemia compared with Klebsiella pneumoniae bacteraemia: risk factors and outcomes. J. Hosp. Infect. 64, 282-287. doi: 10.1016/j.jhin.2006.06.025
Roca, I., Espinal, P., Vila-Farrés, X., and Vila, J. (2012). The Acinetobacter baumannii oxymoron: commensal hospital dweller turned pan-drug-resistant menace. Front. Microbiol. 3:148. doi: 10.3389/fmicb.2012.00148

Rodríguez-Hernández, M. J., Jiménez-Mejias, M. E., Pichardo, C., Cuberos, L., García-Curiel, A., and Pachón, J. (2004). Colistin efficacy in an experimental model of Acinetobacter baumannii endocarditis. Clin. Microbiol. Infect. 10, 581-584. doi: 10.1111/j.1469-0691.2004.00910.x

Roier, S., Zingl, F. G., Cakar, F., Durakovic, S., Kohl, P., Eichmann, T. O., et al. (2016). A novel mechanism for the biogenesis of outer membrane vesicles in gram-negative bacteria. Nat. Commun. 7:a10515. doi: 10.1038/ ncomms 10515

Rumbo, C., Fernández-Moreira, E., Merino, M., Poza, M., Mendez, J. A., Soares, N. C., et al. (2011). Horizontal transfer of the OXA-24 carbapenemase gene via outer membrane vesicles: a new mechanism of dissemination of carbapenem resistance genes in Acinetobacter baumannii. Antimicrob. Agents Chemother. 55, 3084-3090. doi: 10.1128/AAC.00929-10

Rumbo, C., Tomás, M., Fernández Moreira, E., Soares, N. C., Carvajal, M., Santillana, E., et al. (2014). The Acinetobacter baumannii Omp33-36 porin is a virulence factor that induces apoptosis and modulates autophagy in human cells. Infect. Immun. 82, 4666-4680. doi: 10.1128/IAI.02034-14

Runft, D. L., Mitchell, K. C., Abuaita, B. H., Allen, J. P., Bajer, S., Ginsburg, K., et al. (2014). Zebrafish as a natural host model for Vibrio cholerae colonization and transmission. Appl. Environ. Microbiol. 80, 1710-1717. doi: 10.1128/ AEM.03580-13

Russo, T. A., Beanan, J. M., Olson, R., MacDonald, U., Cox, A. D., St. Michael, F., et al. (2013). The K1 capsular polysaccharide from Acinetobacter baumannii is a potential therapeutic target via passive immunization. Infect. Immun. 81, 915-922. doi: 10.1128/IAI.01184-12

Russo, T. A., Beanan, J. M., Olson, R., Macdonald, U., Luke, N. R., Gill, S. R., et al. (2008). Rat pneumonia and soft-tissue infection models for the study of Acinetobacter baumannii biology. Infect. Immun. 76, 3577-3586. doi: 10.1128/IAI.00269-08

Russo, T. A., Luke, N. R., Beanan, J. M., Olson, R., Sauberan, S. L., Macdonald, U., et al. (2010). The K1 capsular polysaccharide of Acinetobacter baumannii strain 307-0294 is a major virulence factor. Infect. Immun. 78, 3993-4000. doi: 10.1128/IAI.00366-10

Rutherford, S. T., and Bassler, B. L. (2012). Bacterial quorum sensing: its role in virulence and possibilities for its control. Cold Spring Harb. Perspect. Med. 2:a012427. doi: 10.1101/cshperspect.a012427

Schilling, D., and Gerischer, U. (2009). The Acinetobacter baylyi hfq gene encodes a large protein with an unusual C terminus. J. Bacteriol. 191, 5553-5562. doi: $10.1128 / \mathrm{JB} .00490-09$

Schmiel, D. H., and Miller, V. L. (1999). Bacterial phospholipases and pathogenesis. Microbes Infect. 1, 1103-1112. doi: 10.1016/S1286-4579(99)00205-1

Sebe, I., Ostorhazi, E., Fekete, A., Kovacs, K. N., Zelko, R., Kovalszky, I., et al. (2016). Polyvinyl alcohol nanofiber formulation of the designer antimicrobial peptide APO sterilizes Acinetobacter baumannii-infected skin wounds in mice. Amino Acids 48, 203-211. doi: 10.1007/s00726-015-2080-4

Senchenkova, S. Y. N., Shashkov, A. S., Popova, A. V., Shneider, M. M., Arbatsky, N. P., Miroshnikov, K. A., et al. (2015). Structure elucidation of the capsular polysaccharide of Acinetobacter baumannii AB5075 having the KL25 capsule biosynthesis locus. Carbohydr. Res. 408, 8-11. doi: 10.1016/j. carres.2015.02.011

Shankar, R., He, L.-K., Szilagyi, A., Muthu, K., Gamelli, R. L., Filutowicz, M., et al. (2007). A novel antibacterial gene transfer treatment for multidrugresistant Acinetobacter baumannii-induced burn sepsis. J. Burn Care Res. 28, 6-12. doi: 10.1097/BCR.0b013e31802c8861

Shlaes, D. M., and Bradford, P. A. (2018). Antibiotics-from there to where? Pathog. Immun. 3, 19-43. doi: 10.20411/pai.v3i1.231

Small, C.-L., McCormick, S., Gill, N., Kugathasan, K., Santosuosso, M., Donaldson, N., et al. (2008). NK cells play a critical protective role in host defense against acute extracellular Staphylococcus aureus bacterial infection in the lung. J. Immunol. 180, 5558-5568. doi: 10.4049/jimmunol.180.8.5558

Smani, Y., McConnell, M. J., and Pachón, J. (2012). Role of fibronectin in the adhesion of Acinetobacter baumannii to host cells. PLoS One 7:e33073. doi: 10.1371/journal.pone.0033073

Smith, M. G., Des Etages, S. G., and Snyder, M. (2004). Microbial synergy via an ethanol-triggered pathway. Mol. Cell. Biol. 24, 3874-3884. doi: 10.1128/ МСB.24.9.3874-3884.2004 
Smith, M. G., Gianoulis, T. A., Pukatzki, S., Mekalanos, J. J., Ornston, L. N., Gerstein, M., et al. (2007). New insights into Acinetobacter baumannii pathogenesis revealed by high-density pyrosequencing and transposon mutagenesis. Genes Dev. 21, 601-614. doi: 10.1101/gad.1510307

Song, X., Zhang, H., Zhang, D., Xie, W., and Zhao, G. (2018). Bioinformatics analysis and epitope screening of a potential vaccine antigen TolB from Acinetobacter baumannii outer membrane protein. Infect. Genet. Evol. 62, 73-79. doi: 10.1016/j.meegid.2018.04.019

Stahl, J., Bergmann, H., Göttig, S., Ebersberger, I., and Averhoff, B. (2015). Acinetobacter baumannii virulence is mediated by the concerted action of three phospholipases D. PLoS One 10:e0138360. doi: 10.1371/journal.pone.0138360

Stock, A. M., Victoria L. Robinson, A., and Goudreau, P. N. (2000). Twocomponent signal transduction. Annu. Rev. Biochem. 69, 183-215. doi: 10.1146/ annurev.biochem.69.1.183

Sugawara, E., and Nikaido, H. (2012). OmpA is the principal nonspecific slow porin of Acinetobacter baumannii. J. Bacteriol. 194, 4089-4096. doi: 10.1128/ JB.00435-12

Sun, B., Hu, X., Liu, G., Ma, B., Xu, Y., Yang, T., et al. (2014). Phosphatase Wip1 negatively regulates neutrophil migration and inflammation. J. Immunol. 192, 1184-1195. doi: 10.4049/jimmunol.1300656

Thuan Tong, T., Mörgelin, M., Forsgren, A., and Riesbeck, K. (2007). Haemophilus influenzae survival during complement-mediated attacks is promoted by Moraxella catarrhalis outer membrane vesicles. J. Infect. Dis. 195, 1661-1670. doi: $10.1086 / 517611$

Tipton, K. A., Dimitrova, D., and Rather, P. N. (2015). Phase-variable control of multiple phenotypes in Acinetobacter baumannii strain AB5075. J. Bacteriol. 197, 2593-2599. doi: 10.1128/JB.00188-15

Tomaras, A. P., Flagler, M. J., Dorsey, C. W., Gaddy, J. A., and Actis, L. A. (2008). Characterization of a two-component regulatory system from Acinetobacter baumannii that controls biofilm formation and cellular morphology. Microbiology 154, 3398-3409. doi: 10.1099/mic.0.2008/019471-0

Touchon, M., Cury, J., Yoon, E.-J., Krizova, L., Cerqueira, G. C., Murphy, C., et al. (2014). The genomic diversification of the whole Acinetobacter genus: origins, mechanisms, and consequences. Genome Biol. Evol. 6, 2866-2882. doi: 10.1093/gbe/evu225

Tsuchiya, T., Nakao, N., Yamamoto, S., Hirai, Y., Miyamoto, K., and Tsujibo, H. (2012). NK1.1+ cells regulate neutrophil migration in mice with Acinetobacter baumannii pneumonia. Microbiol. Immunol. 56, 107-116. doi: 10.1111/j.1348-0421.2011.00402.x

Tsui, H. C., Leung, H. C., and Winkler, M. E. (1994). Characterization of broadly pleiotropic phenotypes caused by an $h f q$ insertion mutation in Escherichia coli K-12. Mol. Microbiol. 13, 35-49. doi: 10.1111/j.1365-2958.1994. tb00400.x

Van Der Sar, A. M., Appelmelk, B. J., Vandenbroucke-Grauls, C. M. J. E., and Bitter, W. (2004). A star with stripes: zebrafish as an infection model. Trends Microbiol. 12, 451-457. doi: 10.1016/j.tim.2004.08.001

Van Faassen, H., Kuolee, R., Harris, G., Zhao, X., Conlan, J. W., and Chen, W. (2007). Neutrophils play an important role in host resistance to respiratory infection with Acinetobacter baumannii in mice. Infect. Immun. 75, 5597-5608. doi: 10.1128/IAI.00762-07

Waggoner, S. N., Reighard, S. D., Gyurova, I. E., Cranert, S. A., Mahl, S. E., Karmele, E. P., et al. (2016). Roles of natural killer cells in antiviral immunity. Curr. Opin. Virol. 16, 15-23. doi: 10.1016/j.coviro.2015.10.008

Wallace, L., Daugherty, S. C., Nagaraj, S., Johnson, J. K., Harris, A. D., and Rasko, D. A. (2016). Use of comparative genomics to characterize the diversity of Acinetobacter baumannii surveillance isolates in a health care institution. Antimicrob. Agents Chemother. 60, 5933-5941. doi: 10.1128/AAC.00477-16
Wand, M. E., Bock, L. J., Turton, J. F., Nugent, P. G., and Sutton, J. M. (2012). Acinetobacter baumannii virulence is enhanced in Galleria mellonella following biofilm adaptation. J. Med. Microbiol. 61, 470-477. doi: 10.1099/ jmm.0.037523-0

Wang, N., Ozer, E. A., Mandel, M. J., and Hauser, A. R. (2014). Genome-wide identification of Acinetobacter baumannii genes necessary for persistence in the lung. MBio 5, e01163-14. doi: 10.1128/mBio.01163-14

Weber, B. S., Harding, C. M., and Feldman, M. F. (2016). Pathogenic Acinetobacter: from the cell surface to infinity and beyond. J. Bacteriol. 198, 880-887. doi: 10.1128/JB.00906-15

Weber, B. S., Kinsella, R. L., Harding, C. M., and Feldman, M. F. (2017). The secrets of Acinetobacter secretion. Trends Microbiol. 25, 532-545. doi: 10.1016/j. tim.2017.01.005

Weber, B. S., Miyata, S. T., Iwashkiw, J. A., Mortensen, B. L., Skaar, E. P., Pukatzki, S., et al. (2013). Genomic and functional analysis of the type VI secretion system in Acinetobacter. PLoS One 8:e55142. doi: 10.1371/journal. pone. 0055142

White, R. M., Sessa, A., Burke, C., Bowman, T., Leblanc, J., Ceol, C., et al. (2008). Transparent adult Zebrafish as a tool for in vivo transplantation analysis. Cell Stem Cell 2, 183-189. doi: 10.1016/j.stem.2007.11.002

Whitfield, C., and Trent, M. S. (2014). Biosynthesis and export of bacterial lipopolysaccharides. Annu. Rev. Biochem. 83, 99-128. doi: 10.1146/annurevbiochem-060713-035600

Wong, D., Nielsen, T. B., Bonomo, R. A., Pantapalangkoor, P., Luna, B., and Spellberg, B. (2017). Clinical and pathophysiological overview of Acinetobacter infections: a century of challenges. Clin. Microbiol. Rev. 30, 409-447. doi: 10.1128/CMR.00058-16

Wright, M. S., Iovleva, A., Jacobs, M. R., Bonomo, R. A., and Adams, M. D. (2016). Genome dynamics of multidrug-resistant Acinetobacter baumannii during infection and treatment. Genome Med. 8, 1-26. doi: 10.1186/s13073016-0279-y

Yan, Z., Yang, J., Hu, R., Hu, X., and Chen, K. (2016). Acinetobacter baumannii infection and IL-17 mediated immunity. Mediat. Inflamm. 2016, 1-5. doi: $10.1155 / 2016 / 9834020$

Yang, H., Chen, G., Hu, L., Liu, Y., Cheng, J., Li, H., et al. (2015). In vivo activity of daptomycin/colistin combination therapy in a Galleria mellonella model of Acinetobacter baumannii infection. Int. J. Antimicrob. Agents 45, 188-191. doi: 10.1016/j.ijantimicag.2014.10.012

Yoon, E.-J., Balloy, V., Fiette, L., Chignard, M., Courvalin, P., and GrillotCourvalin, C. (2016). Contribution of the Ade resistance-nodulation-cell division-type efflux pumps to fitness and pathogenesis of Acinetobacter baumannii. MBio 7, e00697-e00716. doi: 10.1128/mBio.00697-16

Zschiedrich, C. P., Keidel, V., and Szurmant, H. (2016). Molecular mechanisms of two-component signal transduction. J. Mol. Biol. 428, 3752-3775. doi: 10.1016/j.jmb.2016.08.003

Conflict of Interest Statement: The authors declare that the research was conducted in the absence of any commercial or financial relationships that could be construed as a potential conflict of interest.

Copyright (c) 2019 Morris, Dexter, Kostoulias, Uddin and Peleg. This is an openaccess article distributed under the terms of the Creative Commons Attribution License (CC BY). The use, distribution or reproduction in other forums is permitted, provided the original author(s) and the copyright owner(s) are credited and that the original publication in this journal is cited, in accordance with accepted academic practice. No use, distribution or reproduction is permitted which does not comply with these terms. 